\title{
Coerência partidária nas elites parlamentares latino-americanas
}

\author{
Leticia M. Ruiz Rodríguez
}

Universidade de Salamanca

Mercedes García Montero

Universidade de Salamanca

\begin{abstract}
$\underline{\text { Resumo }}$
Este artigo aborda a questão do conteúdo substantivo da competição partidária na América Latina do ponto de vista da coerência intrapartidária. Conceitua-se a coerência partidária como o grau de congruência ideológica e programática dos membros dos partidos. A análise se circunscreve ao grau de coerência da elite parlamentar dos partidos políticos e compreende um total de 25 partidos correspondentes a dez países da região. O trabalho descreve a pauta que segue a coerência nos casos analisados, ensaia uma classificação dos partidos com base nos valores que adquirem nas duas dimensões do conceito (ideológica e programática) e explora o impacto de alguns fatores, tanto relativos ao partido como ao entorno a que pertence, sobre o grau de coerência intrapartidária.
\end{abstract}

Palavras-chave: coerência partidária, partidos políticos, elite parlamentar, América Latina.

\begin{abstract}
This work deals with the substantive content of party competition in Latin America through the analysis of party coherence. Party coherence is conceptualized as the degree of ideological and programmatic congruence among the members of a given party. The analysis is bounded to the parliamentary elite level and it is focused on a total of 25 political parties from 10 countries of the region. This paper describes the pattern followed by coherence for those cases, it offers a ranking of political parties based on the values they adcquire regarding both dimensions of the concept (ideological and programmatic), and it explores the impact of some fators, related both to the party and to its environment, on the degree of party coherence.
\end{abstract}

Key words: party coherence, political parties, parliamentary elites, Latin America. 
Apesar da diversidade dos partidos e sistemas partidários da América Latina, reconhecida tanto pelos estudos teóricos como empíricos, tem havido um receio nesses trabalhos em aprofundar o conteúdo substantivo da competição partidária como elemento que ajuda a entender essa diversidade. Assim, no estudo dos partidos e sistemas partidários da região, as dimensões ideológica e programática da competição partidária tenderam a receber uma menor atenção do que outras questões ${ }^{1}$.

No entanto, paradoxalmente, observa-se na literatura um notável consenso normativo sobre a relação entre partidos fortes, coerentes e coesos e o êxito das consolidações democráticas na América Latina (Diamond, Hartlyn, Linz, Lipset, 1999). Essa convicção deixa transparecer a necessidade de certos níveis de unidade interna dentro dos partidos em seu conteúdo ideológico e programático para que eles sejam funcionais para a democracia. O presente trabalho centra-se no estudo desses níveis de unidade interna a que denominamos coerência partidária.

As páginas que seguem se concentram na análise do grau de congruência entre os membros dos partidos em suas posturas ideológicas e programáticas. 0 objetivo central é analisar a coerência intrapartidária das elites parlamentares de 25 partidos políticos da América Latina nestas duas dimensões (ideológica e programática) por meio de um grupo de indicadores. Os dados que se utilizam pertencem à pesquisa Elites Parlamentares na América Latina que consistiu na aplicação de um questionário a uma amostra representativa de congressistas de dez países da região. ${ }^{2}$

A partir desses indicadores, estabelecemos uma classificação dos partidos de acordo com seu grau de coerência, investigando, além disso, as relações que ocorrem entre a dimensão ideológica e programática da coerência.

Junto com esse objetivo descritivo, estas páginas abordam o poder explicativo de uma série de variáveis exógenas e endógenas sobre os níveis de coerência dos partidos políticos latino-americanos. Por variáveis endógenas entendemos aquelas que adquirem um valor diferente para cada partido (sejam referidas à totalidade do partido ou aos membros deste). Ao contrario, as variáveis exógenas são aquelas cujo valor é o mesmo em todos os partidos de um mesmo sistema político.

\footnotetext{
${ }^{1}$ Em linhas gerais, a questão programática tendeu a ser excluída com mais freqüência do que a ideológica. Algumas exceções são os trabalhos que utilizam o modelo de clivagens e tentam sua aplicação aos sistemas da região (Dix, 1989; Ramos Jiménez, 1995; Moreno ,1999; Mainwaring e Torcal, 2000). Embora a maioria desses trabalhos não analise em detalhe as posições dos partidos em aspectos programáticos, eles proporcionam um panorama das posturas dos partidos com respeito às grandes linhas de divisão. Outros trabalhos que também consideram o programa e a ideologia na lógica partidária latinoamericana são os que analisam a elite partidária e parlamentar (Rosas, 2000; Zechmeister, 2000; Londregan, 1999; Alcántara, 1999; Llamazares e Sandell, 2000; Kitschelt, 2000; Hawkins e Morgenstern, 2000).

${ }^{2}$ Esta pesquisa é dirigida pelo Dr. D. Manuel Alcántara e foi financiada pela CICYT (Ref. SEC95/0845). No Anexo I se encontra uma descrição das características técnicas desse estudo.
} 
O estudo da coerência abordado neste trabalho, além de ser uma contribuição ao conhecimento e análise dos partidos políticos latino-americanos, se aprofunda nos vínculos causais da equação que estabelece uma relação entre a existência de partidos políticos com um conteúdo programático e ideológico mais ou menos definido e a estabilidade-bom funcionamento democrático. Ao lado de ambas as contribuições, o estudo que aqui se apresenta é relevante porque obtém informações sobre as atitudes e valores de uma parte da elite política, ${ }^{3}$ cuja principal função é a representação política a partir da qual se sustentam os princípios democráticos.

Na primeira parte, repassamos o modo como a coerência partidária foi abordada na América Latina. Na segunda parte, explicamos a operacionalização levada a cabo da variável coerência. Nas terceira e quarta partes, apresentamos as principais descobertas de nosso estudo com respeito à variação das dimensões da coerência nos partidos escolhidos e o peso de uma série de variáveis na explicação da coerência, respectivamente. Na quita parte, tiramos conclusões..

\section{O conceito de coerência partidária e seu estudo na América Latina}

A coerência partidária tem sido escassamente considerada na região latinoamericana. Somente a partir de 2000 produziram-se os primeiros esforços para realizar um estudo sistemático sobre a coerência partidária de toda a região (Kitschelt, 2001; Hawkins \& Morgenstern, 2000). Antes dessa data, não se haviam realizado sequer estudos de caso que tratassem do grau de coerência partidária dos partidos que compõem um sistema de partidos determinado, ou que abordassem a coerência de um partido político latino-americano concreto.

Mas ao contrario, existem na literatura alusões ao grau de coerência que os partidos apresentam na América Latina. Desse modo, há um constante reconhecimento da importância de partidos com um certo nível de unidade programática e ideológica, embora, na maioria das ocasiões, a isso não corresponda um significado preciso de coerência, e nunca venha acompanhado por uma conceituação do termo. Poder-se dizer, portanto, que a coerência partidária é mais comumente abordada de um ponto de vista normativo do que na busca de uma descrição ou explicação dos níveis que atinge nos partidos e sistemas partidários da região.

\footnotetext{
${ }^{3}$ Não são muitos os estudos que oferecem dados relativos às elites. Junto aos clássicos de Lipset \& Solari, 1987 e Gunther , 1992, destacam-se a análise de posturas ideológicas e programáticas dos parlamentares que realizam Alcántara, 1995; Alcántara, 1999; Alcántara \& Llamazares, 1997; Crespo \& Mieres, 1997; Martínez, 1997a e b; Ramos, 1997; Londregan, 1999; Llamazares \& Sandell, 2000; Yocelevzky, 1997; Hawkins \& Morgerstern, 2000; Kitschelt, 2001; Rosas \& Zechmeister, 2000.
} 
Vários são os motivos que explicam a desatenção quase sistemática para as questões relacionadas com programa e a ideologia dos partidos, em geral, e para o grau de congruência nas posturas programáticas e ideológicas dos membros dos partidos latino-americanos, em particular. O primeiro motivo se refere ao papel secundário dos partidos políticos em muitos sistemas políticos da região. Isso levou a enfatizar, após os processos de (re)democratização, variáveis relacionadas com a consolidação dos sistemas partidários, segundo a lógica de que somente quando existisse um sistema de partidos identificável e institucionalizado se poderia discutir outras dimensões, como o grau de coerência dos partidos que o compõem. Em segundo lugar, dominou uma tendência a abordar os partidos políticos latinoamericanos como uma avis rara, marcada pela comparação com os partidos existentes em outras regiões geográficas (Europa fundamentalmente). Assim, a afirmação de que os partidos de América Latina são organizações que cumprem funções diferentes das dos partidos políticos ocidentais levou à exclusão de determinadas questões da agenda dos investigadores. O fato de que as elites partidárias na América Latina tenham tendido a utilizar a máquina partidária para a obtenção de poder, sem intenções formais de desenvolver um determinado programa ou ideologia, foi determinante para que se ignorasse o conteúdo das políticas partidárias (fossem idéias, disputas, estratégias...). Em terceiro lugar, a coerência partidária e a dimensão substantiva do jogo partidário em geral, foram muito pouco estudadas por razões de clareza expositiva. Os estudos sobre partidos políticos e sistemas de partidos que paulatinamente proliferaram na região fugiram da inclusão de aspectos problemáticos como o são o programa e a ideologia dos partidos, priorizando o estudo de dimensões alternativas como a volatilidade, a fragmentação, o número efetivo de partidos, entre outras, que facilitam a comparação entre sistemas partidários da região (Coppedge, 1997). Em quarto lugar, se estendemos o argumento de Janda, elaborado para outras regiões, a coerência partidária não foi considerada na literatura sobre partidos na América Latina devido à dificuldade de obter informações sobre os membros dos partidos e à necessidade de investimento de recursos para sua realização (Janda, 1993).

Nessa situação, há uma série de conceitos que se utilizam na literatura sobre partidos políticos de forma equívoca para tratar de idéias próximas da definição de coerência que, apesar de ter vínculos analíticos e empíricos entre si, se referem a aspectos diferentes da lógica partidária. A Tabela 1 é uma tentativa de estabelecer as diferenças entre esses conceitos. Nos conceitos em que a definição dada coincide com a de algum autor, se cita seu nome; no resto dos casos, em que não figura nenhum autor, é porque a definição proposta apresenta alguma diferença com as dos autores que trabalham esses conceitos. 
TABELA 1

Esquema de definições e âmbitos de medição de conceitos relacionados com coerência partidária

\begin{tabular}{|c|c|c|}
\hline & Conceito & Unidade de Análise: partido político \\
\hline \multirow{3}{*}{$\begin{array}{l}\text { Predisposições/ } \\
\text { Opiniões/ } \\
\text { Idéias dos membros } \\
\text { dos partidos }\end{array}$} & Coerência & $\begin{array}{l}\text { Grau de congruência nas posturas ideológicas e } \\
\text { programáticas dos membros de um partido }\end{array}$ \\
\hline & $\begin{array}{l}\text { Cristalização } \\
\text { programática }\end{array}$ & $\begin{array}{l}\text { Grau de simetria das percepções entre os } \\
\text { políticos de todos os partidos sobre o lugar em } \\
\text { que um partido x se situa nos diferentes temas } \\
\text { (Kitschelt, 1999) }\end{array}$ \\
\hline & Faccionalização & $\begin{array}{l}\text { Existência de diversas correntes ideológico- } \\
\text { programáticas dentro de um partido (Hine, 1982) }\end{array}$ \\
\hline \multirow{4}{*}{$\begin{array}{l}\text { Comportamento } \\
\text { dos membros dos } \\
\text { partidos }\end{array}$} & Coesão & $\begin{array}{l}\text { Grau de homogeneidade dos membros de um } \\
\text { partido em seu comportamento } \\
\text { (âmbito legislativo): Inclui disciplina (ou unidade) } \\
\text { e fidelidade partidária } \\
\text { (âmbito de governo): formação de coalizões, análise } \\
\text { de políticas implementadas } \\
\text { (âmbito intrapartidário) }\end{array}$ \\
\hline & Disciplina & $\begin{array}{l}\text { Grau de homogeneidade dos membros de um } \\
\text { partido em seu voto nos órgãos legislativos } \\
\text { Igual à unidade partidária }\end{array}$ \\
\hline & Unidade & $\begin{array}{l}\text { Grau de homogeneidade dos membros de um } \\
\text { partido no voto nos órgãos legislativos } \\
\text { lgual à disciplina partidária }\end{array}$ \\
\hline & $\begin{array}{l}\text { Fidelidade } \\
\text { partidária }\end{array}$ & $\begin{array}{l}\text { Freqüência na mudança de sigla partidária por } \\
\text { parte dos membros de um partido. } \\
\text { Principalmente se usa no contexto dos órgãos } \\
\text { legislativos }\end{array}$ \\
\hline \multirow{2}{*}{$\begin{array}{l}\text { Alude ao partido } \\
\text { político de forma } \\
\text { global sem se referir } \\
\text { aos membros do } \\
\text { partido político }\end{array}$} & Força & $\begin{array}{l}\text { Peso proporcional do partido com respeito ao } \\
\text { resto de partidos em diferentes contextos } \\
\text { (eleições, na legislativa, em uma coalizão...) }\end{array}$ \\
\hline & $\begin{array}{c}\text { Institucionalização } \\
\text { Partidária }\end{array}$ & $\begin{array}{l}\text { Estabilidade das regras e do conteúdo } \\
\text { programático e ideológico }\end{array}$ \\
\hline
\end{tabular}

Fonte: Elaboração própria

Alguns desses nove conceitos foram utilizados indistintamente para referirse a questões distintas e, por sua vez, as mesmas questões foram estudadas com conceitos diferentes. Parte da confusão deriva da criação de conceitos similares aplicados a diferentes níveis da ação política ou do político: contexto eleitoral, contexto dos órgãos legislativos, nível programático-ideológico. Assim a disciplina partidária, a unidade partidária e a fidelidade partidária se referem ao âmbito das 
Assembléias-Poderes-Câmaras Legislativas. A coerência e a cristalização estão mais vinculadas ao âmbito das predisposições e opiniões dos membros dos partidos. ${ }^{4} \mathrm{~A}$ força partidária, em uma de sus acepções, pode referir-se ao âmbito eleitoral. Por sua vez, o conceito de institucionalização abarca mais de um desses âmbitos.

Em alguns casos, uma segunda fonte da confusão conceitual é constituída pela falta de especificação da unidade de análise do conceito. Isso dá lugar a conclusões não muito claras em torno do sistema de partidos a partir da observação dos partidos políticos e vice-versa. ${ }^{5}$ Neste sentido, os conceitos de disciplina, unidade, coesão, coerência, faccionalização e fidelidade partidária são utilizados para medir os partidos e os sistemas partidários sem reelaboração conceitual. O conceito de institucionalização foi utilizado com diferentes matizes conceituais, dependendo de se a unidade era o partido (Levitsky, 1998) ou o sistema partidário (Mainwaring \& Scully, 1995; Schedler, 1995; Mainwaring, 1998), tal como o de cristalização programática (Kitschelt et al., 1999). Os conceitos de fortaleza e fragmentação foram utilizados exclusivamente em um nível de análise, partido e sistema de partidos, respectivamente.

Ao lado de seu uso ambíguo e da falta de clareza na definição da unidade de análise de cada conceito, há uma notável ausência de provas empíricas que permita medir esses conceitos na realidade dos sistemas partidários e dos partidos políticos. ${ }^{6}$ Relacionado com a questão da informação disponível, a escolha dos indicadores desses conceitos se torna complicada e, em alguns casos, utilizam-se os mesmos indicadores para conceitos diferentes (comportamento de voto para disciplina partidária e para coesão partidária) ou o que medem alguns conceitos se tornam indicadores de outros conceitos (fidelidade partidária como indicador de coesão partidária).

Finalmente, não há modelos teóricos que contemplem o modo como esses conceitos variam segundo o tipo de membros do partido que se analise. No entanto, uma conceituação de coerência partidária tem de contemplar a existência de seus diferentes níveis, conforme a implicação dos membros do partido. De maior a menor implicação, pode-se distinguir entre: elite partidária (altos cargos e parlamentares), afiliados do partido sem cargo relevante dentro dele e votantes do partido. ${ }^{7}$ Conforme vai-se descendo de âmbito, seria presumível encontrar níveis menores de conhecimento do programa e da ideologia de um partido.

\footnotetext{
${ }^{4}$ Ao contrário da conceituação de coerência, a cristalização programática não distingue entre questões atitudinais (relacionadas com valores) e questões programáticas. Neste sentido, aspectos relacionados com religião, liberdade, autoritarismo são considerados aspectos programáticos (Kitschelt et al., 1999).

${ }^{5}$ Três rotas de inferência de um nível de análise a outro são as mais habituais na literatura: inferência simples (sem nenhum tipo de reelaboração conceitual); reelaboração conceitual para a aplicação a um nível diferente do que inicialmente foi concebido o conceito; reconhecimento da inaplicabilidade do conceito.

${ }^{6}$ Por exemplo, para o caso da disciplina partidária, é difícil conseguir dados sobre comportamento de voto em alguns órgãos legislativos da região onde não se costuma ter registro individual das votações.

${ }^{7}$ Não obstante, esta tríplice distinção não contempla subdivisões internas que existem entre os três estratos assinalados. Especialmente problemática nesta distinção pode ser a ausência de uma diferenciação entre os membros do partido que não
} 
Nossa conceituação de coerência partidária parte da definição de Janda (1993). Definimos coerência como a congruência (ou sua ausência) nas posturas entre os membros de um partido em aspectos programáticos e ideológicos. ${ }^{8} \mathrm{~A}$ atenção às dimensões programática e ideológica da coerência deixa de lado a análise do componente referido ao comportamento dos membros de um partido nos âmbitos em que desenvolve sua atividade política (âmbito legislativo, esfera de governo e atividades internas do partido). Este componente é mais comumente definido como coesão partidária, com todas as noções que compreende em seu interior (disciplina de voto, fidelidade partidária, responsabilidade do partido...).

A Tabela 2 resume os indicadores de coerência e de coesão partidária nos diferentes níveis de implicação de um indivíduo dentro do partido.

Nossa operacionalização de coerência partidária exclui as percepções dos membros dos partidos com respeito ao resto dos partidos, que são captadas, ao contrário, por conceitos como o de Kitschelt de "cristalização programática" (1999). Quanto mais consenso entre os políticos de outros partidos com respeito à localização de cada um dos partidos, mais nível de cristalização programática nesse determinado partido. A cristalização refere-se às percepções dos outros e a coerência partidária capta as percepções dos próprios membros dos partidos; daí que a primeira seja em nível interpartidário e a segunda, em nível intrapartidário. ${ }^{9}$

compõem a sua elite, as chamadas elites de nível médio, e o resto dos membros de um partido afiliados a ele, mas sem um posto na divisão organizativa. Mesmo assim, dentro dessas elites de nível médio, há quem distinga os chamados ativistas como membros do partido que, desde o ponto de vista de sua atividade, ostentam um papel de destaque dentro do partido. Ademais, esses ativistas se caracterizam por um saber mais sofisticado do programa e da ideologia do partido do que outros membros do partido (Pierre, 1986). Junto a essas duas matizações, também se pode argumentar em torno da necessidade de uma ulterior distinção: os simpatizantes. Essa categoria compreenderia a aqueles que não são membros do partido, mas que estão próximos dele e cuja proximidade é algo superior ao mero apoio eleitoral.

${ }^{8}$ A coerência também pode ser considerada no sistema partidário. Uma operação de adição a partir do grau de coerência dos casos individuais (dos membros do partido) é o método até agora utilizado para calcular o grau de coerência do sistema partidário. Mas também se pode chegar a uma consideração a partir da análise de programas dos partidos políticos e determinar sua evolução no tempo em termos de posturas que defendem nos mesmos temas ao longo do tempo. Um terceiro modo de medir a coerência sistêmica é analisar as superposições dos partidos. O grau de congruência das posturas desses partidos ao longo do tempo e o grau em que estas posturas se superpõem ou, ao contrário, ocupam espaços ideológicoprogramáticos diferentes que justificam sua existência como unidades partidárias autônomas. Por exemplo, Sani e Sartori elaboraram um índice de superposição referido a aspectos ideológicos (Sani e Sartori 1983). Também se pode fazer o mesmo com questões programáticas. A coerência, portanto, tem dois níveis: sistêmico e individual. O primeiro tem como unidade de análise os partidos políticos e o segundo, os membros dos partidos. A unidade de medida, em ambos os casos, são os membros dos partidos.

${ }^{9}$ Por isso, talvez este aspecto das percepções é mais próximo da coerência no nível do sistema partidário, já que se conceituou a coerência partidária em nível intrapartidário, enquanto que a sistêmica é mais interpartidária. 
TABELA 2

Comparação da medição da coerência partidária e coesão partidária

\begin{tabular}{|c|c|c|c|}
\hline & \multicolumn{2}{|c|}{ COERÊNCIA PARTIDÁRIA } & COESÃO PARTIDÁRIA \\
\hline & \multicolumn{3}{|c|}{ INDICADORES } \\
\hline NÍVEL DE MEDIDA & Programa & Ideologla & Comportamento \\
\hline $\begin{array}{l}\text { Elite partidária } \\
\text { (altos cargos do } \\
\text { partido e } \\
\text { parlamentares } \\
\text { pertencentes ao } \\
\text { partido) }\end{array}$ & $\begin{array}{l}\text { Posturas em diferentes } \\
\text { temas (issues) que se } \\
\text { discutem na arena política }\end{array}$ & $\begin{array}{c}\text { Localização } \\
\text { ideológica }\end{array}$ & $\begin{array}{l}\text {. Voto na Assembléia } \\
\text { legislativa } \\
\text {. Formação de coalizões } \\
\text { e pactos } \\
\text {. Políticas } \\
\text { implementadas uma vez } \\
\text { no governo } \\
\text {. Voto em atividade } \\
\text { partidária-interna }\end{array}$ \\
\hline $\begin{array}{l}\text { Outros membros } \\
\text { filiados ao } \\
\text { partido }\end{array}$ & $\begin{array}{c}\text { Posturas em diferentes } \\
\text { temas (issues) que se } \\
\text { discutem na arena política }\end{array}$ & $\begin{array}{l}\text { Localização } \\
\text { ideológica }\end{array}$ & $\begin{array}{l}\text {. Voto em eleições } \\
\text {.Voto em atividade } \\
\text { partidária interna }\end{array}$ \\
\hline $\begin{array}{l}\text { Votantes do } \\
\text { partido não } \\
\text { filiados }\end{array}$ & $\begin{array}{c}\text { Posturas em diferentes } \\
\text { temas (issues) que se } \\
\text { discutem na arena política }\end{array}$ & $\begin{array}{l}\text { Localização } \\
\text { ideológica }\end{array}$ & . Voto em eleições \\
\hline
\end{tabular}

Fonte: Elaboração própria

\section{Operacionalização do conceito de coerência partidária no estudo das elites parlamentares}

O Quadro 1 mostra de forma gráfica a operacionalização que realizamos do conceito de coerência a partir das perguntas do questionário da pesquisa sobre Elites parlamentares na América Latina. ${ }^{10}$ A coerência partidária na dimensão ideológica é medida por meio da autolocalização ideológica dos parlamentares na escala clássica em ciências sociais de 1-10, em que 1 é esquerda e 10 é direita.

Dentro da dimensão programática, estabeleceram-se duas subdimensões: programática-atitudinal e programática-econômica. A subdimensão programáticaatitudinal engloba as predisposições das elites em temas valorativos; tradicionalmente, esses temas serviram para caracterizar os partidos em eixos do tipo conservador-progressista. A subdimensão programático-econômica foi definida a partir das posturas dos legisladores em temas que se discutem na arena econômica.

\footnotetext{
${ }^{10}$ Uma descrição detalhada do modo como as perguntas foram feitas, assim como suas recodificações, encontra-se no Anexo II.
} 
QUADRO 1

Operacionalização da coerência partidária

Definição de coerência partidária: grau de congruência dos membros dos partidos em suas posturas ideológicas e programáticas.

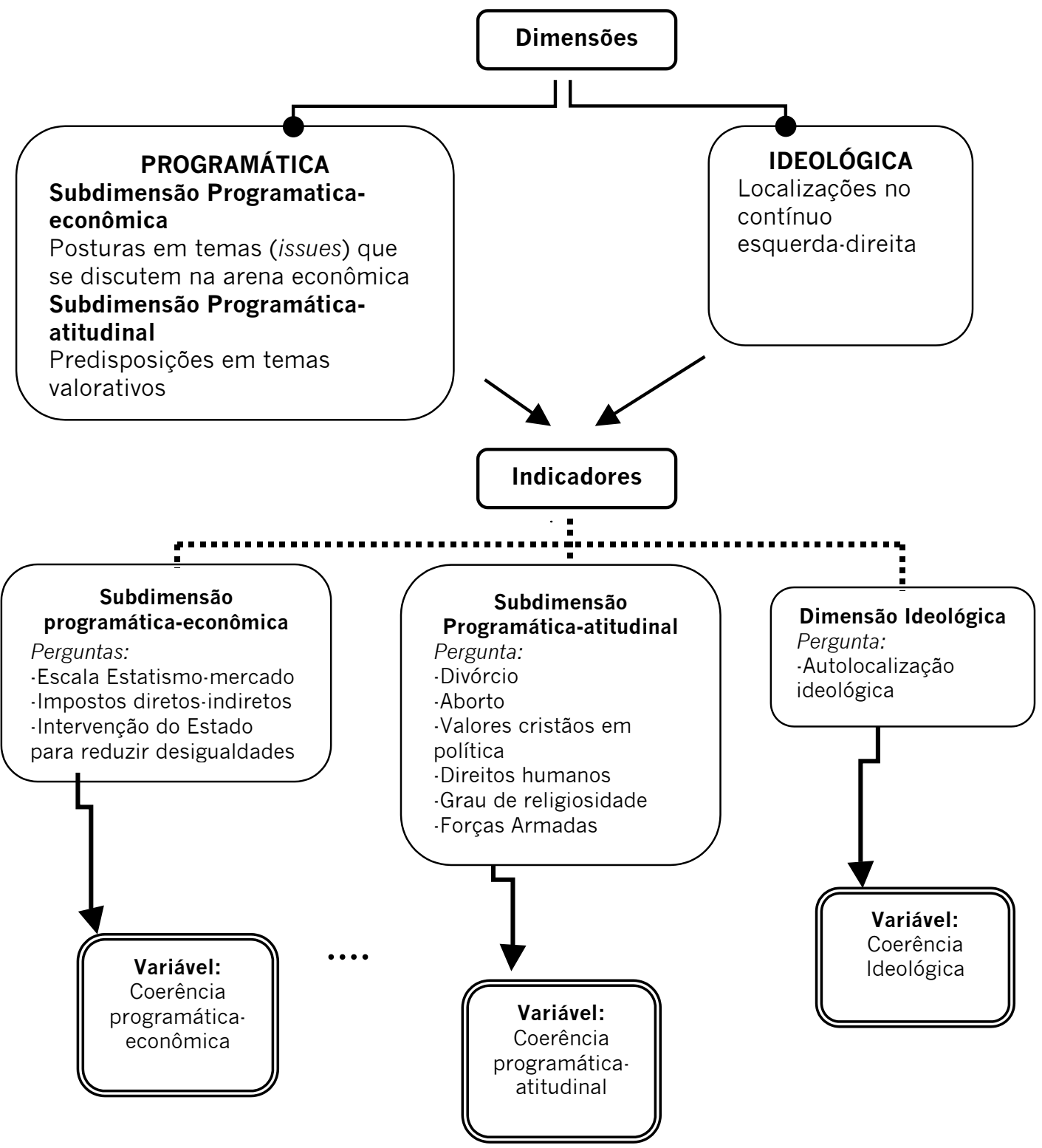


Uma parte da escolha das perguntas para cada uma das dimensões foi condicionada pelo modo como as respostas haviam sido codificadas. Existe um problema no fato de que sejam as mesmas perguntas para todos os países, pois em alguns casos as perguntas não são relevantes ou ativas politicamente em uma conjuntura dada. Além disso, a coerência partidária na subdimensão programáticaeconômica foi medida através das posturas dos legisladores em três perguntas que, dado seu conteúdo quase exclusivamente econômico, não contemplam outros aspectos relevantes da dimensão programática, como podem ser as posturas dos partidos perante a descentralização ou a globalização. Entendemos que uma parte fundamental de fazer política no governo está relacionada com o tratamento dos temas econômicos, e isso foi especialmente relevante na América Latina, onde ficou obsoleta a assim chamada matriz-estadocêntrica, ${ }^{11}$ na qual a atuação do Estado teve uma relevância direta para as perspectivas de bem-estar pessoal de grande parte da população. A mudança do papel do Estado, como conseqüência direta das políticas neoliberais, teve repercussões para os partidos como organizadores da mediação entre a sociedade e o Estado. Nesse contexto, estas perguntas destinam-se a aprofundar a visão de como os partidos entendem como deve agir um governo nos temas econômicos.

Para comprovar o grau de coerência dos partidos estudados, utilizou-se o desvio padrão ${ }^{12}$ (mostra a que distância da média se encontram os resultados individuais). Escolheu-se o desvio padrão em vez da porcentagem modal, utilizada em Hawkins e Morgenstern (2000), porque se considera que, embora esta seja muito útil quando se trata de variáveis nominais ou dicotômicas, leva a conclusões enganosas em variáveis de escala, ao não levar em conta toda a dispersão do contínuo. Utiliza-se essa medida para descrever o grau de discrepância que os legisladores revelam nas dimensões e subdimensões da variável coerência. A partir dela, calculamos a média dos desvios típicos dos indicadores para cada uma das dimensões da coerência. ${ }^{13}$ Estas três médias servem para classificar os partidos de acordo com seu grau de coerência programática-atitudinal, programática-

\footnotetext{
${ }^{11}$ A Matriz-Estado-Cêntrica se baseava em dois mecanismos complementares que lhe permitiam um equilíbrio: de um lado, estava a relação entre o Estado e o mercado, a regulação política da economia e, mais especificamente, dos fluxos de capital e, de outro, a Matriz relacionava o Estado e a sociedade civil mediante agências e políticas encarregadas de pôr em marcha diferentes tipos de controles, diretos e indiretos, sobre a participação política e social. Essa matriz, que teve vigência na América Latina desde a década de 1930, foi ineficaz para enfrentar as restrições imprevistas ou aproveitar os espaços que se abriram no sistema internacional, não teve flexibilidade e sua ineficácia foi aumentando a partir da década de 1970. Sobre essas questões, ver (Cavarozzi, 1995).

${ }^{12}$ A variância é a média das diferenças ao quadrado de $n$ pontuações com respeito a sua média aritmética. Expressa a variabilidade das pontuações dos sujeitos na variável que estamos estudando. A raiz quadrada da variância se denomina desvio padrão (S). A diferença entre ambas é dada pelo fato de que a variância se expressa em unidades ao quadrado, ao passo que o desvio padrão é expresso na mesma escala que a variável à que nos referimos.

${ }^{13}$ Os indicadores a partir dos quais construímos as dimensões da variável dependente não estão medidos na mesma escala. Por isso, tivemos de decidir entre dicotomizá-los todos ou deixá-los em suas escalas naturais, no caso de variáveis ordinais. Finalmente, nos decidimos por esta última opção porque consideramos que a primeira poderia supor uma grave distorção da medição. Esta decisão conduz a que só se pode comparar os partidos em cada dimensão e não as dimensões entre si, o que, dado o objetivo de nosso estudo (classificar os partidos de acordo com seu grau de coerência) é pertinente.
} 
econômica e ideológica. Ademais, com essas médias calculamos um índice total de coerência-incoerência que contempla as dimensões e subdimensões para cada um dos partidos analisados. ${ }^{14}$

\section{A coerência ideológica e programática nas elites parlamentares latino-americanas}

\section{Coerência ideológica}

Na Tabela 3 aparecem os partidos políticos que estudamos ordenados de menor a maior coerência na dimensão ideológica. A coerência ideológica média dos partidos latino-americanos analisados neste estudo é 1,38. Dos 25 partidos analisados, 14 estão acima dessa média de coerência ideológica, isto é, apresentam maior incoerência nesta dimensão do que a coerência ideológica por termo médio. Os dez partidos mais incoerentes ideologicamente se situam em posições de direita: suas médias de localização ideológica são superiores a 5,00, com exceção do PRE, do MVR (ambos partidos de corte eminentemente populista e com forte liderança carismática), e a DP (que na legislatura 1998-2003 contou com numerosos deputados que não provinham originariamente das fileiras do partido).

Portanto, parece existir uma relação, que posteriormente se comprovará, entre posições de direita e incoerência. Nesse mesmo sentido, observa-se, ao analisar os partidos mais coerentes, que com exceção de dois partidos (os chilenos RN e UDI), as médias de autolocalização ideológica são inferiores a cinco, ou seja, mais próximas da esquerda.

Por outro lado, existe grande variação no grau de coerência ideológica nos partidos analisados. O PLC nicaragüense é o partido mais incoerente ideologicamente $(1,97)$ e o PPD chileno, o mais coerente $(0,70)$. Entre os dois há 1,27 pontos de diferença no desvio padrão.

Os três partidos mais incoerentes ideologicamente são fruto de divisões. 0 PLC nicaragüense surgiu como uma organização de notáveis, com uma estrutura de quadros pouco cristalizada e fruto de uma fração do partido oficial do regime autoritário somozista. Na atualidade, é uma agremiação de direita de corte radical, mas, sobretudo, seu elemento principal é seu caráter anti-sandinista, que inclui um componente "neoautoritário" e um estilo basicamente populista (Santiuste, 2001), encarnado até as eleições de novembro de 2001 na figura de Arnoldo Alemán. O segundo partido com grau mais alto de incoerência ideológica é o PNH hondurenho,

14 Os desvios padrões que se adicionam estão medidos em escalas diferentes. No entanto, entendemos que não é problemático posto que para cada partido variam as escalas dos desvios nas mesmas perguntas e da mesma forma. Isto é, todos os partidos sofrem a mesma distorção, de tal forma que ao comparar os partidos em cada dimensão e na dimensão total, que é nosso objetivo, o problema desaparece. 
que também surge de uma divisão. Seu alto grau de dispersão ideológica se manifesta também na existência de diversas facções no interior do partido. Por seu lado, o PRE equatoriano é também fruto de uma divisão e, tal como no PLC nicaragüense, destaca-se a influência personalista do líder, Abdalá Bucaram, nos desígnios do partido e no caráter fortemente populista da agremiação.

TABELA 3

Médias de localização ideológica e desvios típicos (ordenados de menor a maior coerência)

\begin{tabular}{|l|l|l|l|}
\hline País-Ano & Partidos & Média & Desvio padrão \\
\hline Nicarágua 98 & PLC & 6,69 & 1,97 \\
\hline Honduras 98 & PNH & 7,03 & 1,94 \\
\hline Equador 98 & PRE & 4,14 & 1,93 \\
\hline Guatemala 98 & PAN & 6,03 & 1,93 \\
\hline Venezuela 00 & AD & 5,56 & 1,85 \\
\hline Venezuela 00 & MVR & 3,64 & 1,69 \\
\hline Equador 98 & DP & 4,47 & 1,66 \\
\hline Honduras 98 & PLH & 5,65 & 1,65 \\
\hline Equador 98 & PSC & 6,76 & 1,61 \\
\hline El Salvador 00 & ARENA & 7,67 & 1,59 \\
\hline Guatemala 98 & FRG & 4,93 & 1,54 \\
\hline Colômbia 98 & PL & 4,60 & 1,53 \\
\hline Rep. Dominicana 00 & PLD & 4,24 & 1,46 \\
\hline Nicarágua 98 & FSLN & 2,63 & 1,39 \\
\hline Colômbia 98 & PC & 6,69 & 1,20 \\
\hline Argentina 98 & PJ & 5,10 & 1,18 \\
\hline Rep. Dominicana 00 & PRD & 4,85 & 1,17 \\
\hline Chile 98 & RN & 6,71 & 1,16 \\
\hline Argentina 98 & FREPASO & 3,05 & 1,03 \\
\hline El Salvador 00 & FMLN & 1,94 & 1,00 \\
\hline Chile 98 & UDI & 0,97 \\
\hline Equador 98 & ID & 7,94 & 0,90 \\
\hline Argentina 98 & UCR & 4,06 & 0,78 \\
\hline Chile 98 & DC & 0,74 \\
\hline Chile 98 & PPD & 0,70 \\
\hline Coerência ideológica média & 1,38 \\
\hline E & 4,09 & \\
\hline
\end{tabular}

Fonte: Elaboração própria a partir de dados da pesquisa "Elites parlamentares na América Latina" 
Mas nem sempre a incoerência ideológica se relaciona com um partido originado por divisões. Por exemplo, o PAN da Guatemala, posicionado ideologicamente na direita liberal e com a presença de um líder carismático, mostra um grau alto de dispersão na dimensão ideológica da coerência, mas sua origem está na iniciativa de um grupo de empresários.

Descendo nos níveis de incoerência, aparecem dois partidos venezuelanos. Desde suas origens, a AD da Venezuela esteve marcada por profundos conflitos, os quais provocaram varias divisões nesta organização. Após a ascensão ao poder de Hugo Chávez, em 1998, o partido parece ter entrado em uma fase de "hibernação", ausentando-se dos importantes processos sóciopolíticos vividos pelo país (Vaivads, 2001). Esses elementos podem ajudar a compreender a dispersão mostrada pelas elites na dimensão ideológica. Outro partido venezuelano, o MVR, mantém desvios típicos altos na dimensão ideológica. Esse movimento é novo e carece de solidez interna, na medida em que se encontra inserido em um processo de desenvolvimento da personalização política que o país vem passando desde 1993, como mecanismo de estabilização frente à deterioração do sistema de partidos. Sua dispersão na dimensão ideológica reflete-se na própria definição do partido, no sentido em que se anuncia em seus Estatutos como um "movimento político amplo, aberto e unitário" (Pereira, 2001).

Ao contrário dos partidos mais incoerentes na dimensão ideológica que provêm de uma diversidade de áreas geográficas da região, os partidos com maior coerência ideológica, com exceção do ID do Equador, a FMLN de El Salvador e o PRD dominicano, são partidos concentrados em dois países: Chile e Argentina. Vejamos cada um deles.

A UCR argentina é um partido com uma longa história política, enquanto que a FREPASO é uma força política nova e heterogênea em seu interior, onde convergem dirigentes e militantes de base de diferentes agremiações. Apesar disso e embora mostre uma dispersão ideológica maior que a UCR, ainda assim ela é comparativamente baixa. Isso parece indicar que a juventude de um partido não é impedimento para que exista coerência ideológica.

No caso chileno, é notável o maior grau de coerência da UDI em relação a $\mathrm{RN}$, dois partidos de direita com postulados programático-ideológicos muito similares. A UDI, partido mais à direita e com maior identificação com o legado autoritário do regime pinochetista, parece apresentar menores divisões internas do que a RN. Os membros da UDI se identificam claramente com o passado pinochetista e apresentam um maior grau de acordo em suas posturas do que a $\mathrm{RN}$, um partido que representa uma direita mais aberta e mais desmarcada da herança de Pinochet, e que nasce da divisão da UDI e do Movimento União Nacional. 
A ID destaca-se pela baixa dispersão mostrada por suas elites. O motivo dessa coerência pode estar na adesão, desde o momento de sua fundação e ao longo de sus história, aos princípios da social-democracia e na inexistência de um líder carismático que controle, de forma personalista, a atuação da agremiação.

A FMLN é o principal partido político da esquerda salvadorenha e, tal como a FREPASO argentina, esteve formada desde sua origem por agrupações diversas e distintas que parecem unidas pela ideologia, de modo que, apesar dos sucessivos e variados conflitos internos pelos quais passou, mantém-se a coincidência da elite no momento de se situar ideologicamente.

É importante ressaltar a variação no grau de coerência partidária entre partidos de um mesmo sistema partidário. Por exemplo, os partidos do Equador e de El Salvador analisados apresentam importantes diferenças em seu grau de coerência ideológica. Isso confirma a necessidade de enfocar os estudos de coerência desde a perspectiva dos partidos políticos, contra a tendência a generalizações em torno dos sistemas partidários. A exceção a este fato está nos casos do sistema de partidos da Venezuela e do Chile: embora em posições opostas -Venezuela com partidos incoerentes ideologicamente e Chile com partidos coerentes nesse terreno -, as agremiações que compõem cada um desses sistemas partidários apresentam graus de coerência ideológica similares ao resto dos partidos de seu sistema.

\section{Coerência programática}

\section{Coerência programática-atitudinal}

A subdimensão programática-atitudinal total mostra uma alta variação entre os partidos mais e menos coerentes. A coerência programática-atitudinal média é 1,34 unidades de desvio padrão. Treze partidos estão acima dessa média. A variação nesta dimensão é entre 1,60 e 1,35, menor, portanto, do que no caso da dimensão ideológica.

Nos postos de maior coerência estão dois partidos chilenos (UDI e PPD). Os três partidos mais incoerentes na soma da dimensão atitudinal são a FRG de Guatemala, ${ }^{15}$ o PRE equatoriano e o MVR venezuelano. ${ }^{16}$ Os três compartilham a característica de uma liderança fortemente carismática: Ríos Montt, Abdalá Bucaram e Hugo Chávez, respectivamente. Esses líderes são fundadores e dirigem seus partidos de forma extremamente personalista. Isso pode fazer com que dentro do partido exista uma adesão motivada pela liderança, mais do que por princípios programático-atitudinais.

\footnotetext{
${ }^{15}$ A história política deste partido está repleta de contradições e inconsistências de estratégia e ação, reflexo de sua condição de plataforma eleitoral submetida às ambições do líder fundador: José Efraín Ríos Montt (García Díez, 2001)

${ }^{16}$ Cabe recordar que os dois últimos partidos também se mostraram incoerentes na dimensão ideológica.
} 
TABELA 4

Subdimensão programática-atitudinal (ordenados de menor a maior coerência)

\begin{tabular}{|c|c|c|c|c|c|c|c|c|}
\hline País-Ano & Partido & $\begin{array}{l}\text { Papel } \\
\text { das } \\
\text { Forças } \\
\text { Armadas }\end{array}$ & $\begin{array}{l}\text { Grau de } \\
\text { religio- } \\
\text { sidade }\end{array}$ & \begin{tabular}{|c|} 
Valores \\
cristãos ou \\
seculares \\
em política
\end{tabular} & Divórcio & Aborto & $\begin{array}{l}\text { Direitos } \\
\text { humanos }\end{array}$ & $\begin{array}{c}\text { Média } \\
\text { Coerên- } \\
\text { cia } \\
\text { progra- } \\
\text { mática } \\
\text { atitudinal }\end{array}$ \\
\hline Guatemala 98 & FRG & 2,08 & 2,89 & 1,54 & 1,55 & 1,23 & 0,36 & 1,60 \\
\hline Equador 98 & PRE & 2,37 & 2,66 & 1,33 & 1,54 & 1,39 & 0,29 & 1,59 \\
\hline Venezuela 00 & MVR & 1,48 & 2,48 & 1,85 & 1,36 & 1,66 & 0,47 & 1,55 \\
\hline Guatemala 98 & PAN & 2,16 & 2,51 & 1,33 & 1,71 & 1,04 & 0,48 & 1,53 \\
\hline Nicarágua 98 & PLC & 1,85 & 2 & 1,57 & 1,73 & 1,45 & 0,50 & 1,51 \\
\hline Nicarágua 98 & FSLN & 1,93 & 2,95 & 1,12 & 1,13 & 1,53 & 0,36 & 1,50 \\
\hline Venezuela 00 & $A D$ & 1,89 & 2,62 & 0,93 & 1,49 & 1,66 & 0,45 & 1,50 \\
\hline Equador 98 & PSC & 1,68 & 2,59 & 1,39 & 1,45 & 1,06 & 0,51 & 1,44 \\
\hline El Salvador 00 & FMLN & 2,01 & 2,01 & 2,61 & 0,83 & 0,88 & 0,24 & 1,43 \\
\hline El Salvador 00 & ARENA & 1,33 & 1,87 & 1,97 & 1,51 & 1,28 & 0,51 & 1,41 \\
\hline Equador 98 & DP & 1,69 & 2,17 & 0,96 & 1,63 & 1,36 & 0,49 & 1,38 \\
\hline Argentina 98 & UCR & 1,81 & 2,42 & 1,15 & 0,96 & 1,39 & 0,51 & 1,37 \\
\hline Equador 98 & ID & 0,70 & 2,50 & 1,27 & 1,77 & 1,52 & 0,33 & 1,34 \\
\hline Honduras 98 & $\mathrm{PNH}$ & 2,10 & 1,72 & 0,96 & 1,78 & 1,01 & 0,43 & 1,33 \\
\hline Colômbia 98 & $\mathrm{PL}$ & 2,18 & 2,03 & 1,23 & 0,63 & 1,60 & 0,31 & 1,33 \\
\hline Colômbia 98 & PC & 2 & 2,09 & 1,01 & 1,08 & 1,35 & 0,39 & 1,32 \\
\hline Argentina 98 & PJ & 1,51 & 2,16 & 1,14 & 1,05 & 1,54 & 0,50 & 1,31 \\
\hline Chile 98 & $\mathrm{DC}$ & 1,78 & 1,82 & 1,10 & 1,48 & 1,04 & 0,50 & 1,28 \\
\hline Rep.Dom. 00 & PLD & 1,71 & 1,71 & 1,23 & 1,23 & 1,04 & 0,45 & 1,22 \\
\hline Honduras 98 & PLH & 1,83 & 1,66 & 0,88 & 1,34 & 1,11 & 0,50 & 1,22 \\
\hline Chile 98 & RN & 1,77 & 2,18 & 1,17 & 1,59 & 0 & 0,47 & 1,19 \\
\hline Argentina 98 & FREPASO & 1,53 & 2,02 & 1,41 & 0,67 & 0,94 & 0,50 & 1,17 \\
\hline Rep. Dom. 00 & PRD & 1,09 & 1,87 & 1,21 & 1,24 & 1,04 & 0,50 & 1,15 \\
\hline Chile 98 & UDI & 1,26 & 1,59 & 1,09 & 1,69 & 0,73 & 0,24 & 1,1 \\
\hline Chile 98 & PPD & 1,11 & 1,44 & 1,06 & 0 & 1,42 & 0,49 & 0,92 \\
\hline & & & & \multicolumn{4}{|c|}{ Coerência programática-atitudinal média } & 1,34 \\
\hline
\end{tabular}

Fonte: Elaboração própria a partir de dados da pesquisa "Elites parlamentares na América Latina"

Por outro lado, quanto às semelhanças por país, nos casos de Nicarágua, El Salvador, Colômbia e Chile, dois partidos em cada um desses países apresentam na subdimensão programática-atitudinal níveis parecidos (ocupam postos seguidos), o que mostra que esta subdimensão da coerência pode ter mais explicações de tipo exógeno do que a dimensão ideológica. No exame em separado dos indicadores 
utilizados para construir o índice de coerência programática-atitudinal, na valoração do papel das Forças Armadas não existem semelhanças entre os partidos de um mesmo país. O que indicaria, uma vez mais, que a variação dessa valoração é mais abordável desde o ponto de vista do partido do que do sistema partidário. Além disso, esse indicador mostra uma grande variação nas pontuações dos desvios típicos, o que evidencia que a valoração das Forças Armadas é um tema polêmico dentro dos partidos latino-americanos. As elites partidárias que apresentam uma maior incoerência em sua visão das Forças Armadas são as do PRE equatoriano e as do PL colombiano. No lado da coerência, são as de ID e as do PPD chileno que mantêm um grau menor de dispersão.

O grau de religiosidade também exibe desvios altos nos partidos analisados, mostrando que as elites de um mesmo partido não possuem níveis similares de prática religiosa. Neste indicador, o partido mais incoerente é o guatemalteco FRG e o chileno PPD é o mais coerente. Curiosamente, a DC, que nasce com um marcado caráter religioso, ostenta um nível alto de dispersão no grau de religiosidade de seus membros.

Ao comparar os níveis de coerência no papel das Forças Armadas e no grau de religiosidade, os partidos são mais coerentes na segunda do que na primeira questão. As únicas exceções a essa tendência são a FMLN, o PLH de Honduras e o $\mathrm{PL}$ de Colômbia, partidos em que a definição do papel das Forças Armadas apresenta menos dissensão entre os legisladores do que seu grau de religiosidade. ${ }^{17}$

Destaca-se o grau de homogeneidade que apresentam os legisladores com respeito à presença de valores cristãos ou seculares em política. As exceções são a FMLN da Nicarágua e o MVR venezuelano, que mostram mais dispersão em seu interior.

Na opinião sobre o divórcio, ressalta o caso do PPD, já que seus legisladores manifestaram uma total coerência em suas opiniões. No lado oposto, aparecem o PNH hondurenho e a ID do Equador, partido este que em outros indicadores não se destaca pela incoerência.

O aborto, ao contrário do que se poderia esperar, devido ao caráter polêmico do tema, concentra pontuações menos dispersas do que o divórcio. Os legisladores são mais coerentes na hora de posicionar-se contra ou a favor. Neste indicador, outro partido chileno volta a se destacar por sua coerência total, desta vez o RN. No pólo oposto, como mais incoerente em relação às posições contra ou a favor do aborto, estão os dois partidos venezuelanos analisados: AD e MVR. O último indicador que compõe a subdimensão programática-atitudinal é a

\footnotetext{
${ }^{17}$ As escalas das perguntas, como indica o Anexo III, não são iguais nas sete perguntas que compõem o índice de coerência programático-atitudinal. Por isso, para comentar o grau de coerência programático-atitudinal, só se podem comparar os níveis de desvio padrão de perguntas com as mesmas escalas (papel das forças armadas e grau de religiosidade, por um lado; e aborto, divórcio e presença de valores cristãos em política, por outro lado).
} 
importância concedida aos direitos humanos ou das minorias étnicas ou culturais. Os partidos que se mostram mais coerentes neste tema são a FMLN de El Salvador e a UDI de Chile. Ao contrário, o PSC doe Equador, a Arena de El Salvador e a UCR da Argentina são os que apresentam mais incoerência.

\section{Coerência programática-econômica}

No índice total de dispersão da subdimensão programática-econômica voltam a figurar nas posições mais incoerentes o MVR ${ }^{18}$ e o PRE, seguidos por outro partido equatoriano, o PSC e os dois colombianos (PL e PC). ${ }^{19}$ Entre os partidos com mais coerência nesta dimensão, destacam-se os argentinos PJ e FREPASO e os chilenos UDI e PPD.

Relacionado com a posição dos partidos enquanto membros de um mesmo sistema, observa-se que em Equador, Colômbia, Nicarágua e Argentina, dois partidos em cada um dos casos apresentam níveis parecidos na dimensão programática (ocupam postos seguidos).

Contrariamente ao que o saber convencional poderia sugerir, os partidos do Chile não ocupam os primeiros postos no grau de coerência e exibem o menor grau de coerência no âmbito programático-econômico, diferente dos altos níveis de coerência no âmbito ideológico e programático-atitudinal. Por sua vez, os partidos chilenos mostram as maiores diferenças entre si neste âmbito programáticoeconômico. Dada a tradicional ideologização da política chilena e a relevância da clivagem religiosa, bem como de alguns valores que essa clivagem insere no jogo político do país, é esperável encontrar maiores níveis de acordo nas dimensões ideológica e programática-atitudinal.

$\mathrm{Na}$ análise por indicadores, cabe ressaltar que os partidos não mostram níveis muito altos de incoerência na escala estatismo-mercado, o que assinalaria que não se trata mais de um tema que desperte grandes diferenças de opinião entre a elite dos partidos. As agremiações partidárias que mostram maior incoerência neste indicador são o PRE e o MVR, que, como se viu ao longo da análise, ocupam, com muito freqüência, os níveis mais altos de incoerência. Depois deles vem o PSC equatoriano. E ao contrario, o partido mais coerente volta a ser um chileno, PPD, seguido da ID do Equador.

\footnotetext{
${ }^{18}$ Em "La propuesta de Hugo Chávez para gobernar Venezuela" esboça-se o desenvolvimento de uma economia humanista (dirigida para melhorar as condições de vida do homem), autogerida (democratizar a economia e promover organizações alternativas para a produção: associações, cooperativas) e competitiva (aproveitar vantagens comparativas e competitivas no mercado interno e externo, poupança interna e investimento estrangeiro). Expressa-se a complementaridade entre mercado e Estado, na qual este último teria um papel importante na busca do interesse geral e o desenvolvimento (Pereira, 2001).

${ }^{19}$ Esta subdimensão, ao ser comparada com o resto de dimensões, é a que apresenta pontuações mais baixas de desvio. Isso se deve ao fato de que é composta por duas variáveis dicotomizadas, nas quais o desvio padrão nunca pode passar de 1 . Isso leva necessariamente a que a comparação seja entre os partidos que compõem as dimensões e não entre as mesmas.
} 
TABELA 5

Subdimensão programática-econômica (ordenados de menor a maior coerência)

\begin{tabular}{|c|c|c|c|c|c|}
\hline País-Ano & Partido & $\begin{array}{l}\text { Estatismo- } \\
\text { mercado }\end{array}$ & $\begin{array}{l}\text { Impostos } \\
\text { diretos- } \\
\text { indiretos }\end{array}$ & $\begin{array}{c}\text { Intervenção do } \\
\text { Estado como via } \\
\text { para reduzir } \\
\text { desigualdades }\end{array}$ & $\begin{array}{c}\text { Média } \\
\text { coerência } \\
\text { programática } \\
\text { econômica }\end{array}$ \\
\hline Venezuela 00 & MVR & 1,10 & 0,51 & 0,49 & 0,7 \\
\hline Equador 98 & PRE & 1,12 & 0,50 & 0,48 & 0,7 \\
\hline Equador 98 & PSC & 1,03 & 0,50 & 0,49 & 0,67 \\
\hline Colômbia 98 & $\mathrm{PL}$ & 1,10 & 0,51 & 0,36 & 0,65 \\
\hline Colômbia 98 & PC & 0,99 & 0,51 & 0,46 & 0,65 \\
\hline Rep. Dom. 00 & PRD & 0,99 & 0,51 & 0,45 & 0,65 \\
\hline El Salvador 00 & ARENA & 0,91 & 0,44 & 0,50 & 0,61 \\
\hline Venezuela 00 & $A D$ & 0,80 & 0,50 & 0,51 & 0,60 \\
\hline Guatemala 98 & PAN & 0,89 & 0,43 & 0,50 & 0,60 \\
\hline Honduras 98 & PN & 0,95 & 0,42 & 0,41 & 0,59 \\
\hline Nicarágua 98 & PLC & 0,89 & 0,44 & 0,44 & 0,59 \\
\hline Nicarágua 98 & FSLN & 0,77 & 0,51 & 0,49 & 0,59 \\
\hline Equador 98 & DP & 0,77 & 0,48 & 0,49 & 0,58 \\
\hline Honduras 98 & $\mathrm{PL}$ & 0,84 & 0,45 & 0,42 & 0,57 \\
\hline Rep. Dom. 00 & PLD & 0,84 & 0,45 & 0,41 & 0,56 \\
\hline Chile 98 & RN & 0,66 & 0,47 & 0,48 & 0,53 \\
\hline Guatemala 98 & FRG & 0,83 & 0,32 & 0,43 & 0,52 \\
\hline El Salvador 00 & FMLN & 0,76 & 0,39 & 0,37 & 0,50 \\
\hline Chile 98 & $\mathrm{DC}$ & 0,72 & 0,32 & 0,41 & 0,48 \\
\hline Argentina 98 & UCR & 0,71 & 0,48 & 0 & 0,39 \\
\hline Equador & ID & 0,49 & 0,29 & 0,39 & 0,39 \\
\hline Chile 98 & UDI & 0,62 & 0,50 & 0 & 0,37 \\
\hline Argentina 98 & PJ & 0,69 & 0,40 & 0 & 0,36 \\
\hline Argentina 98 & FREPASO & 0,82 & 0,24 & 0 & 0,35 \\
\hline Chile 98 & PPD & 0,43 & 0,47 & 0 & 0,3 \\
\hline & & & \multicolumn{2}{|c|}{$\begin{array}{l}\text { Coerência programática- } \\
\text { econômica média }\end{array}$} & 0,54 \\
\hline
\end{tabular}

Fonte: Elaboração própria a partir de dados da pesquisa "Elites parlamentares na América Latina" 
Quanto à preferência por impostos diretos ou indiretos para financiar o Estado, a FREPASO argentina e a ID equatoriana são os que se destacam pela coerência oferecida pelos legisladores na hora de declarar-se por um tipo de imposto ou outro. No lado oposto, e manifestando mais dispersão, encontram-se o MVR, os dois partidos colombianos analisados (PL e PC), o PRD da República Dominicana e a FSLN nicaragüense.

$\mathrm{Na}$ opinião dos legisladores sobre a intervenção do Estado como via para reduzir as desigualdades, destaca-se o alto número de partidos que manifestam total coerência. ${ }^{20}$ Entre eles, estão os três partidos argentinos analisados (PJ, UCR, e FREPASO), o que leva a pensar que esta coerência pode ter uma explicação exógena para este país em particular. Também são totalmente coerentes o PPD chileno e a também chilena UDI. Os partidos mais incoerentes neste indicador são a AD da Venezuela, a Arena de EI Salvador e o PAN da Guatemala.

\section{Coerência total}

A coerência total varia entre 1,49 e 0,64. O PRE equatoriano e o PPD chileno são o menos e o mais coerente dos 25 casos analisados. Na Tabela 6 aparece a média total dos desvios típicos nas três dimensões para todos os partidos políticos. $^{21}$

Tal como parecia sugerir a análise individual das dimensões, os partidos chilenos - três dos quatro estudados - são os mais coerentes (DC, UDI, PPD). Por isso, talvez caiba esperar explicações exógenas para esse país. Ao contrário, o PRE destaca-se por sua incoerência, seguido do PAN guatemalteco e dos dois partidos venezuelanos, MVR e AD. Um segundo aspecto que se confirma, tal como vínhamos sugerindo, se refere à utilidade do partido político como unidade de análise. Por exemplo, contra o que seria de se esperar, um partido chileno, o RN, aparece em nossa análise como menos coerente do que três partidos argentinos (FREPASO, UCR, PJ) e um partido equatoriano (ID).

\footnotetext{
${ }^{20}$ Isso pode se dever ao fato de que, em princípio, não se trata de um tema que gere polêmica. Embora no momento de pô-lo em prática possa se converter em um tema gerador de discrepâncias.

${ }^{21}$ Nossa classificação dos partidos se distingue da de Hawkins e Morgenstern (2000) na seleção de países, no fato de que eles utilizam dados de questionários realizados em 1994 e porque os resultados que eles obtêm são agregados. Ou seja, eles analisam a coerência sistêmica, não a partidária, ao menos no indicador de coerência total (coesão para eles). Nós optamos por um enfoque que prioriza a análise do partido, em vez do sistema. Isso nos permite encontrar uma fotografia mais detalhada das diferenças entre partidos de um mesmo sistema. Apesar dessas diferenças, é possível fazer algum tipo de comparação entre os dois trabalhos. Em termos gerais, as duas análises concluem que Chile e Equador ocupam os lugares de maior e menor coerência. As duas diferenças mais importantes são o lugar que designamos para a Venezuela em nossa análise, que é dos sistemas com partidos mais incoerentes, enquanto que no caso de Hawkins e Morgenstern, esse país ocupa um lugar intermediário entre onze países; e a Colômbia, onde ocorre o contrário: segundo nossa análise, esse ocupa um lugar intermediário, enquanto que no trabalho deles ocupa um lugar de baixa coerência.
} 
TABELA 6

Os partidos nas três dimensões (ordenados de menos a mais coerente)

\begin{tabular}{|l|l|c|c|c|c|}
\hline \multicolumn{1}{|c|}{ País-ano } & Partido & $\begin{array}{c}\text { Subdimensão } \\
\text { programática- } \\
\text { econômica }\end{array}$ & $\begin{array}{c}\text { Subdimensão } \\
\text { programática- } \\
\text { atitudinal }\end{array}$ & $\begin{array}{c}\text { Dimensão } \\
\text { ideológica }\end{array}$ & $\begin{array}{c}\text { Média total } \\
\text { coerência }\end{array}$ \\
\hline \hline Equador 98 & PRE & 0,7 & 1,59 & 1,93 & 1,40 \\
\hline Guatemala 98 & PAN & 0,6 & 1,53 & 1,93 & 1,35 \\
\hline Venezuela 00 & MVR & 0,7 & 1,55 & 1,69 & 1,31 \\
\hline Venezuela 00 & AD & 0,6 & 1,5 & 1,85 & 1,31 \\
\hline Equador 98 & PSC & 0,67 & 1,44 & 1,61 & 1,24 \\
\hline Honduras 98 & PN & 0,59 & 1,33 & 1,94 & 1,28 \\
\hline Guatemala 98 & FRG & 0,52 & 1,6 & 1,54 & 1,22 \\
\hline Equador 98 & DP & 0,58 & 1,38 & 1,66 & 1,20 \\
\hline El Salvador 00 & ARENA & 0,61 & 1,41 & 1,59 & 1,20 \\
\hline Honduras 98 & PL & 0,57 & 1,33 & 1,65 & 1,18 \\
\hline Nicarágua 98 & PLC & 0,59 & 1,22 & 1,97 & 1,17 \\
\hline Nicarágua 98 & FSLN & 0,59 & 1,5 & 1,39 & 1,16 \\
\hline Colômbia 98 & PL & 0,65 & 1,33 & 1,53 & 1,15 \\
\hline Rep. Dom. 00 & PLD & 0,56 & 1,22 & 1,46 & 1,08 \\
\hline Colômbia 98 & PC & 0,65 & 1,32 & 1,2 & 1,05 \\
\hline Rep. Dom. 00 & PRD & 0,65 & 1,15 & 1,17 & 0,99 \\
\hline El Salvador 00 & FMLN & 0,5 & 1,43 & 1 & 0,97 \\
\hline Chile 98 & RN & 0,53 & 1,19 & 1,16 & 0,96 \\
\hline Argentina 98 & PJ & 0,36 & 1,31 & 1,18 & 0,95 \\
\hline Equador 98 & ID & 0,39 & 1,34 & 0,9 & 0,87 \\
\hline Argentina 98 & FREPASO & 0,35 & 1,17 & 1,03 & 0,85 \\
\hline Argentina 98 & UCR & 0,39 & 1,37 & 0,78 & 0,84 \\
\hline Chile 98 & DC & 0,48 & 1,28 & 0,74 & 0,83 \\
\hline Chile 98 & UDI & 0,37 & 1,1 & 0,97 & 0,81 \\
\hline Chile 98 & PPD & 0,3 & 0,92 & 0,7 & 0,64 \\
\hline Fonte: Elator & Média da coerência total & $\mathbf{1 , 0 8}$ \\
\hline
\end{tabular}

Fonte: Elaboração própria a partir de dados da pesquisa "Elites parlamentares na América Latina" 


\section{Vínculos entre dimensões}

A Tabela 7 resume a posição que os partidos mais coerentes e os mais incoerentes ocupam nas dimensões e subdimensões estudadas e na total.

\section{TABELA 7}

Os dez partidos mais coerentes-incoerentes nos cruzamentos dimensionais (em negrito, os que aparecem em todas as dimensões)

\begin{tabular}{|c|c|c|c|c|}
\hline & $\mathrm{ca}$ & udinal & & otal \\
\hline $\begin{array}{c}\text { Incoerentes } \\
\text { (A ordem é } \\
\text { de maior à } \\
\text { menor } \\
\text { incoerência) }\end{array}$ & $\begin{array}{l}\text { PLC (Nicarágua) } \\
\text { PNH (Honduras) } \\
\text { PRE (Equador) } \\
\text { PAN (Guatemala) } \\
\text { AD (Venezuela) } \\
\text { MVR (Venezuela) } \\
\text { DP (Equador) } \\
\text { PLH (Honduras) } \\
\text { PSC (Equador) } \\
\text { ARENA (El Salv.) }\end{array}$ & $\begin{array}{l}\text { FRG (Guatemala) } \\
\text { PRE (Equador) } \\
\text { MVR (Venezuela) } \\
\text { PAN (Guatemala) } \\
\text { PLC (Nicarágua) } \\
\text { FSLN (Nicarágua) } \\
\text { AD (Venezuela) } \\
\text { PSC (Equador) } \\
\text { FMLN (EI Salv.) } \\
\text { ARENA (El Salv.) }\end{array}$ & $\begin{array}{l}\text { MVR (Venezuela) } \\
\text { PRE (Equador) } \\
\text { PSC (Equador) } \\
\text { PL (Colômbia) } \\
\text { PC (Colômbia) } \\
\text { PRD (Rep Dom.) } \\
\text { ARENA (El Salv.) } \\
\text { AD (Venezuela) } \\
\text { PAN (Guatemala) } \\
\text { PNH (Honduras) }\end{array}$ & $\begin{array}{l}\text { PRE (Equador) } \\
\text { PAN (Guatemala) } \\
\text { MVR (Venezuela) } \\
\text { AD (Venezuela) } \\
\text { PSC (Equador) } \\
\text { PNH (Honduras) } \\
\text { FRG (Guatemala) } \\
\text { DP (Equador) } \\
\text { ARENA (EI Salv.) } \\
\text { PL (Honduras) }\end{array}$ \\
\hline $\begin{array}{l}\text { Coerentes } \\
\text { (A ordem é } \\
\text { de maior à } \\
\text { menor } \\
\text { coerência) }\end{array}$ & $\begin{array}{l}\text { PPD (Chile) } \\
\text { DC (Chile) } \\
\text { UCR (Argentina) } \\
\text { ID (Equador) } \\
\text { UDI (Chile) } \\
\text { FMLN (EI Salv.) } \\
\text { FREPASO (Argent.) } \\
\text { RN (Chile) } \\
\text { PRD (Rep. Dom.) } \\
\text { PJ (Argentina) }\end{array}$ & $\begin{array}{l}\text { PPD (Chile) } \\
\text { UDI (Chile) } \\
\text { PRD (Rep. Dom.) } \\
\text { FREPASO (Argent.) } \\
\text { RN (Chile) } \\
\text { PUSC (Costa Rica) } \\
\text { PL (Honduras) } \\
\text { PLD (Rep. Dom.) } \\
\text { DC (Chile) } \\
\text { PJ (Argentina) }\end{array}$ & $\begin{array}{l}\text { PPD (Chile) } \\
\text { FREPASO (Argent.) } \\
\text { PJ (Argentina) } \\
\text { UDI (Chile) } \\
\text { ID (Equador) } \\
\text { UCR (Argentina) } \\
\text { DC (Chile) } \\
\text { FMLN (El Salvador) } \\
\text { FRG (Guatemala) } \\
\text { RN (Chile) }\end{array}$ & $\begin{array}{l}\text { PPD (Chile) } \\
\text { UDI (Chile) } \\
\text { DC (Chile) } \\
\text { UCR (Argentina) } \\
\text { FREPASO } \\
\text { (Argent.) } \\
\text { ID (Equador) } \\
\text { PJ (Argentina) } \\
\text { RN (Chile) } \\
\text { FMLN (EI Salv.) } \\
\text { PRD (Rep Dom.) }\end{array}$ \\
\hline
\end{tabular}

Fonte: Elaboração própria a partir de dados da pesquisa "Elites parlamentares na América Latina"

Os partidos que repetem posições incoerentes em todas as dimensões tratadas são: o PRE e PSC do Equador, o PAN da Guatemala e o MVR e a AD da Venezuela. Ao examinarmos os partidos que ocupam posições incoerentes, observamos que são os da região centro-americana os que as ocupam mais vezes e que os partidos que os acompanham nessas posições, situados no sul do continente, são dos países andinos: Venezuela e Equador. A Venezuela passou nos últimos anos por um processo de decomposição do sistema bipartidário tradicional que a caracterizava. As eleições de 1993 marcam um ponto de ruptura com o 
esquema político consolidado a partir de 1973, para dar início a uma situação de multipartidarismo. Os principais partidos políticos tradicionais venezuelanos, AD e COPEI, enfrentaram nas disputas eleitorais de 1998 novos partidos surgidos em função de lideranças pessoais e com objetivos eleitorais. Assim surgiu o MVR, para apoiar a candidatura presidencial de Hugo Chávez Frías, candidato que finalmente ganhou as eleições e dirigiu, com um estilo muito personalista, uma série de mudanças importantes e estruturais no país. A legitimidade dos partidos está prejudicada e isso explica a dificuldade que encontram os novos movimentos sociais para consolidar fidelidades e inserir-se nas organizações sociais. Um sinal disso é a crescente personalização da política em torno de lideranças nacionais e regionais (Molina, 2001).

Por outro lado, o Equador passou nos últimos anos por diversas crises de governo, como a de Abdalá Bucaram em 1997 e a de Jamil Mahuad em 2000. Os partidos políticos equatorianos sofrem uma extrema polarização, à que se acrescentam pautas pouco cooperativas. Ademais, tal como no caso venezuelano, caracterizam-se pela personalização da política, variável segundo o partido, e embora os partidos estejam consolidados como estrutura de oportunidades políticoeleitorais, continuam tendo problemas para gerar fidelidades na sociedade. A todos esses elementos é preciso acrescentar a forte regionalização do país que faz com que os partidos tenham problemas para se introduzir nos espaços que não são seus feudos históricos.

No que tange aos partidos mais coerentes, os que repetem posições de coerência nas três dimensões pertencem todos ao Cone Sul: quatro partidos chilenos (PPD, UDI, DC e RN) e dois partidos argentinos (FREPASO e PJ). A UCR, o outro partido argentino analisado, embora se destaque por sua coerência na subdimensão programática-econômica e na dimensão ideológica, ocupa uma posição intermediária na subdimensão programática-atitudinal. Nessa situação também se encontram outros partidos, como a ID do Equador e a FMLN de EI Salvador. Por sua vez, o PRD dominicano, embora mantenha posturas coerentes na dimensão ideológica e na subdimensão programática-atitudinal, apresenta posturas incoerentes na subdimensão programática-econômica. Dessas observações pode-se extrair a conclusão de que a subdimensões da dimensão programa não estão relacionadas. Para comprovar como se relacionam as dimensões e subdimensões da coerência definidas neste trabalho, fez-se uma análise de correlação (Tabela 8).

A dimensão ideológica se correlaciona significativamente com as subdimensões programática-econômica $(0,54)$ e, em especial, com a programáticaatitudinal $(0,76)$. Ademais, esta correlação é positiva, o que nos indica que desvios típicos altos na dimensão ideológica se correlacionam com desvios altos na dimensão programática. Ou seja, a coerência ideológica está muito relacionada com a coerência programática-econômica e com a programática-atitudinal e se um 
partido é incoerente ideologicamente, tenderá a sê-lo programaticamente. No entanto, embora significativa estatisticamente no nível 0,05, é baixa a correlação entre as subdimensões da dimensão programa. Por isso, pode-se afirmar que as posturas coerentes ou incoerentes de um determinado partido quanto a suas atitudes têm pouca relação com o grau de coerência programática-econômica desse partido. Este fato reforça a distinção da coerência programática em duas subdimensões, tal como se fez neste trabalho.

\section{TABELA 8}

Correlações das dimensões e subdimensões

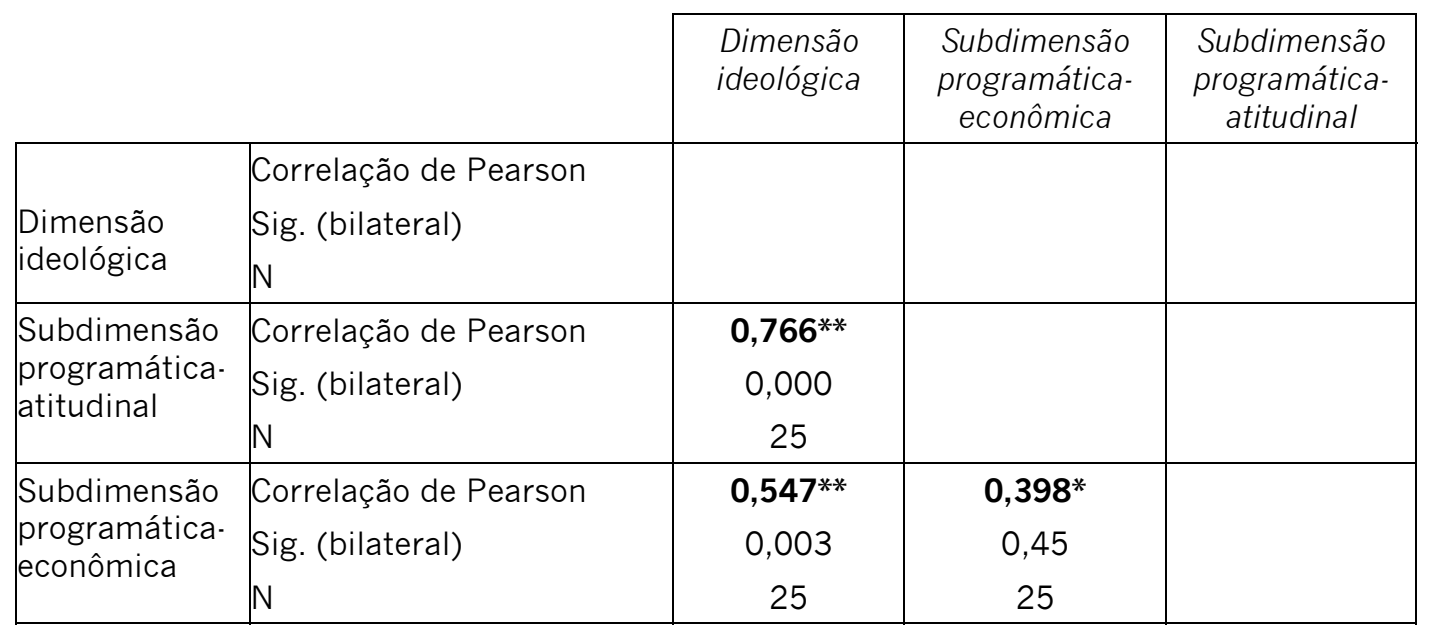

${ }^{* \star}$ A correlação é significativa no nível 0,01 (bilateral).

\section{Para uma explicação da coerência partidária}

As variáveis explicativas que a literatura sugere quando aborda, embora de forma tangencial, a questão da coerência partidária podem ser classificadas em dois grandes grupos de variáveis. Como mostra a Tabela 9, por um lado a literatura misturou variáveis que se referem ao sistema, aqui denominadas variáveis exógenas, e, por outro lado, variáveis endógenas, aquelas que assumem um valor diferente em cada partido. ${ }^{22}$

\footnotetext{
${ }^{22}$ A direção da relação entre os diferentes grupos de variáveis e a importância-difusão-projeção do programático e ideológico nos partidos e sistemas de partidos ainda foi determinada com clareza: o que para alguns autores favorece a importância do programático, para outros funciona no sentido contrário. Neste sentido, a dificuldade de determinar não somente o peso, mas a direção, pode contribuir para a existência de efeitos mútuos entre a dimensão partidária e exógena da coerência partidária. Por exemplo, o personalismo pode levar a uma menor coerência programática e ideológica, mas ao mesmo tempo, uma menor coerência partidária pode facilitar a chegada e aquisição de protagonismo de líderes personalistas.
} 
TABELA 9

Variáveis destacadas na literatura por seus efeitos sobre o grau de coerência partidária (e/ou conceitos próximos)

\section{Variáveis exógenas}

(afetam todos os partidos do sistema partidário)

Forma de governo do sistema político

Linz e Valenzuela, 1994; Maor, 1997

Sistema eleitoral do país (tipo de lista, cláusula de reeleição, tipo de circunscrições)

Mainwaring y Shugart, 1997; Hawkins y Morgenstern, 2000

Número de partidos do sistema partidário

Hartlyn y Valenzuela, 1998; Downs, 1957; Hawkins y Morgenstern, 2000

Grau de polarização do sistema partidário

Sartori, 1991; Downs, 1957

Tradição de líderes, caudilhos do país

Alexander, 1973

Número de anos de democracia de forma ininterrupta

Hartlyn, Diamond, Lipset, Linz, 1999

Tipos de clivagens do sistema de partidos

Middlebrook, 2000

Arranjos socioeconômicos do país

Kitschelt, 2000 y 2001

Variáveis endógenas

(seu valor é diferente em cada partido, afetam os partidos políticos de forma individual)

Tipo de recrutamento e indicação de candidatos dentro do partido

Norris, 1997; Hawkins y Morgenstern, 2000

Apelo a diferentes classes por parte do partido (caráter policlassista ou não do partido)

Presença/Existência de líderes fortes dentro do partido

Bowler et al., 1999

Ideologia do partido

Idade do partido

Hawkings y Morgenstern, 2000

Fonte: Elaboração própria

Com o modelo de explicação da coerência partidária que propomos pretendemos determinar o peso real de fatores que a literatura sobre partidos e o saber convencional apontam como responsáveis pelos níveis de consenso/dissenso intrapartidário, mas cujo peso real, ao contrário, não se costuma comprovar empiricamente.

As explicações monocausais são insuficientes para explicar a coerência dos partidos. Tanto as variáveis exógenas como as endógenas têm incidência na 
coerência partidária, embora atuem em níveis distintos: as variáveis exógenas colocariam um nível geral de (in)coerência para os partidos que compõem um sistema partidário, ao fazer parte de uma mesma lógica institucional e histórica. Ao contrário, as variáveis endógenas, que assumem valores diferentes por partido, seriam relevantes para dar conta das diferenças na coerência partidária de partidos pertencentes a um mesmo sistema. ${ }^{23}$ Assim, em nosso modelo explicativo de coerência intrapartidária introduzimos aspectos endógenos referidos ao partido e referidos aos legisladores (a sua trajetória profissional e socialização) junto com duas variáveis exógenas.

A Tabela 10 detalha as variáveis do modelo que propomos. A ideologia de um partido político se perfila como um dos elementos endógenos ao partido com influência sobre o grau de congruência dos membros dos partidos. Os partidos de esquerda da região, por terem padecido períodos longos de proscrições e perseguições por parte dos regimes imperantes, interiorizaram mecanismos de fidelidade ao partido que os leva a ser mais coerentes até hoje. Junto com a ideologia, a idade é apontada como outro elemento gerador de coerência dentro de um partido: aqueles que têm com uma longa história adquirem uma estrutura ideológica e programática mais assentada do que os mais jovens, que estão em processo de gênese e debate. Ainda no grupo de variáveis endógenas, mas referida aos legisladores, vemos que o número de anos de militância e a experiência parlamentar conduzem a uma maior assimilação das regras dos partidos e a um maior contato com seu programa e ideologia. Portanto, os partidos formados por políticos com maior número de anos em organizações partidárias e/ou maior experiência parlamentar tenderão a ser mais coerentes. Com respeito à socialização política, percebe-se que um processo básico da coerência partidária é a socialização: os partidos que contam com militantes que discutiram sobre temas políticos tenderão a ser mais coerentes.

No grupo de variáveis exógenas, o número de partidos políticos parece influir no grau de coerência, embora a direção dessa relação não esteja clara na literatura, uma vez que existe uma espécie de evidência contraditória. Aqui comprovamos se um menor número de partidos conduz a mais difusão programática e ideológica no interior dos mesmos e, portanto, à menor coerência. Ao lado dessa variável, o grau de desenvolvimento socioeconômico incide sobre elementos da estabilidade e consolidação dos sistemas políticos. Nesse sentido, queremos contrastar a aparência de que os partidos mantêm mais coerência nos países com mais desenvolvimento socioeconômico.

\footnotetext{
${ }^{23}$ No trabalho de Hawkins e Morgenstern (2000), aquele que de uma maneira mais empírica aborda a questão das variáveis explicativas, as três variáveis que se consideram são: a variável endógena idade do partido e as variáveis exógenas: leis eleitorais e número de partidos.
} 
TABELA 10

Variáveis introduzidas para a explicação da coerência partidária

\begin{tabular}{|l|l|l|}
\hline \multicolumn{2}{|l|}{ Variáveis Endógenas } & Variáveis Exógenas \\
\hline Referidas a cada partido & Referidas aos legisladores & \\
\hline \multirow{2}{*}{ Ideologia do Partido 24} & Média de anos de militância & $\begin{array}{l}\text { Número efetivo de partidos na } \\
\text { última legislatura }\end{array}$ \\
\cline { 2 - 3 } & $\begin{array}{l}\text { Repetição de cargo } \\
\text { legislativo }\end{array}$ & $\begin{array}{l}\text { Grau de desenvolvimento } \\
\text { econômico do país. }\end{array}$ \\
\hline Idade do Partido & $\begin{array}{l}\text { Freqüência com que se } \\
\text { falava de política em sua } \\
\text { infância }\end{array}$ & \\
\hline
\end{tabular}

Nota: No Anexo II indica-se o modo como se construíram as variáveis independentes.

Fonte: Elaboração própria

Para determinar o peso e contrastar a direção das relações entre as variáveis independentes estabelecidas e a coerência partidária realizaram-se várias análises de regressão múltipla pelo procedimento de passos sucessivos. ${ }^{25} \mathrm{Na}$ Tabela 11 aparece o resumo dos resultados obtidos com a análise multivariável. ${ }^{26}$

\section{Dimensão coerência ideológica}

Duas das variáveis propostas no modelo aparecem com influência significativa sobre o grau de coerência partidária: o desenvolvimento econômico do país e a ideologia do partido. Ambas explicam $43 \%$ da variância da coerência ideológica. Através do estatístico $\mathrm{F}$, sabemos que a relação que se estabelece entre as duas variáveis da regressão e a coerência ideológica é uma relação linear significativa. Obtemos o peso relativo de cada variável independente na equação de regressão ao analisar os Betas estandardizados. Assim, vemos que embora ambas guardem uma relação significativa com a coerência ideológica de um partido e que conjuntamente expliquem 43\%, não têm igual peso relativo: a variável exógena, desenvolvimento econômico do país, é o elemento que mais explica os níveis de

\footnotetext{
${ }^{24}$ Considerou-se relevante a utilização da ideologia do partido como fator explicativo da coerência. Diante da possível crítica em torno da tautologia deste modelo, já que o elemento ideológico constitui uma dimensão da variável dependente coerência, enfatizamos que a dimensão ideológica da variável dependente é a coerência, portanto, o relevante é a dispersão. Ao passo que, no caso da ideologia como independente, é uma média e o que importa nela é seu valor substantivo.

${ }^{25} \mathrm{O}$ conceito de relação se refere ao grau de variação conjunta existente entre duas variáveis ou mais. Com a técnica estatística que aplicaremos, buscamos relações lineares.

${ }^{26}$ Comprovaram-se os supostos das análises de regressão realizadas para garantir sua validade. O suposto da linearidade é cumprido por nosso modelo, comprovado através da análise dos gráficos de dispersão. Com respeito ao suposto de independência, na Tabela 11, os valores do estatístico Durbin-Watson indicam que podemos assumir independência porque em nenhum caso este estatístico assume valores distintos dos compreendidos entre 1,5 e 2,5. Em relação aos supostos de homocedasticidade e normalidade, analisaram-se os resíduos comprovando que as variâncias são homogêneas. Por último, exploramos que não existe colinearidade entre as variáveis independentes, os índices de condição são todos menores que 15 .
} 
coerência ideológica de um partido político. Esta relação se estabelece no sentido de que os partidos situados em países com maior desenvolvimento econômico têm maior probabilidade de possuir coerência ideológica.

A variável endógena, ideologia do partido, com menor peso explicativo, nos indica que os partidos de esquerda são mais coerentes ideologicamente do que os partidos de direita. Mas tal como observamos na classificação partidária da coerência ideológica, a existência de dois partidos (PRE e MVR) com fortes lideranças personalistas e com graus de incoerência ideológica altos que se situam na esquerda debilita a força dessa relação.

\section{Dimensão coerência programática}

\section{Subdimensão coerência programática-atitudinal}

A análise multivariável da coerência programática-atitudinal dos partidos políticos sugere que somente pode ser explicada em $15 \%$ pelo desenvolvimento econômico. Essa relação é muito pobre, apesar de ser significativa e, quanto à direção, a influência seria no sentido de que os partidos situados em países desenvolvidos economicamente são mais coerentes na dimensão programáticaatitudinal do que os localizados em países com baixo desenvolvimento econômico ${ }^{27}$.

$\mathrm{Na}$ análise por indicadores, a dispersão existente dos legisladores na valoração do papel das Forças Armadas de seu país é explicada em 33\% pelo número efetivo de partidos nas últimas eleições legislativas. O sentido dessa relação é que os partidos dos países com maior número efetivo de partidos tendem a manter mais coerência na valoração das Forças Armadas do que os partidos pertencentes a países com um número pequeno de partidos.

Com respeito à dispersão das elites partidárias na inclinação pela presença de valores cristãos ou seculares em política, na análise de regressão múltipla se encontrou que há duas variáveis que influem nesta inclinação e que explicam 40\% da variação da dispersão de um determinado partido na hora de decidir-se por valores cristãos ou seculares em política. A variável com maior peso relativo na explicação é de caráter endógeno: a idade do partido (os partidos com mais anos de atividade política tendem a ser mais coerentes na hora de decidir-se por valores cristãos ou seculares em política). A outra variável da equação de regressão com influência significativa, embora com um peso explicativo inferior, é de caráter exógeno: o número efetivo de partidos nas últimas eleições legislativas (os partidos pertencentes a países com alto número efetivo de partidos são mais coerentes na

\footnotetext{
${ }^{27}$ As variáveis independentes que introduzimos não têm influência, pelo menos estatisticamente significativa, nos seguintes indicadores da subdimensão programática-atitudinal: grau de religiosidade e importância concedida aos direitos humanos e das minorias étnicas e culturais.
} 
inclinação por valores cristãos ou seculares em política do que os partidos de países com baixo número efetivo de partidos).

A variação da dispersão das elites partidárias diante do divórcio é explicada em 29\% por duas variáveis endógenas: a ideologia do partido e a freqüência com que os legisladores falavam de política durante sua infância. A ideologia do partido é a que tem um peso explicativo maior no sentido de que os partidos de esquerda mantêm posturas mais coerentes com relação ao divórcio. Embora com menor peso explicativo do que a ideologia do partido, é significativa a relação que se estabelece entre a variável de socialização política "freqüência com que se falava de política na infância" e a coerência dos legisladores com respeito ao divórcio (os partidos cujos legisladores viveram em ambientes em que se falava de política tendem a manifestar mais coerência na postura perante o divórcio).

No que tange à coerência intrapartidária diante do aborto, a análise de regressão mostra três variáveis que explicam $42 \%$ da variância da coerência ou incoerência dos partidos na hora de se posicionar frente ao aborto. Essas variáveis, em ordem de importância relativa quanto a sua influência são: a média de anos de militância partidária dos legisladores, o desenvolvimento econômico do país (outra vez esta variável indica que os partidos situados em países com alto desenvolvimento econômico são mais inclinados a assumir posturas coerentes na opinião sobre o aborto) e o nível de estudos.

Nessa subdimensão é onde se encontrou mais peso explicativo de variáveis endógenas. Contudo, a variável com maior potência explicativa, tal como na dimensão ideológica da coerência, é o desenvolvimento econômico do país. Esses resultados sugerem que se deve explorar os mecanismos causais que intervêm na relação entre coerência e desenvolvimento econômico.

\section{Subdimensão coerência programática-econômica}

A coerência programática-econômica é explicada pelo desenvolvimento econômico do país em 20\%. A dispersão do indicador estatismo-mercado que se utilizou para construir a subdimensão da coerência programática-econômica é somente explicada, em uma porcentagem baixa (20\%), pelo desenvolvimento econômico do país em que se encontra o partido político. Essa relação possui o mesmo sentido que as descritas anteriormente: partidos situados em países com alto desenvolvimento econômico tendem a ser mais coerentes na hora de posicionar-se em uma escala estatismo-mercado.

Por seu lado, a coerência na opinião das elites partidárias sobre a intervenção do Estado como via para reduzir desigualdades é explicada pelo desenvolvimento econômico do país em que se encontra o partido. A essa variável explicativa, embora com um peso relativo menor, une-se o nível de estudos dos 
legisladores do partido: juntas, elas explicam 33\% da variação da coerência dos partidos perante a questão da intervenção do Estado como via para reduzir as desigualdades.

\section{Coerência total}

A coerência partidária total só mantém relação linear significativa com a variável exógena desenvolvimento econômico do país. Essa variável explica 33\% da coerência partidária e, tal como se estabeleceu a relação dessa variável com o resto dos indicadores das dimensões e subdimensões, os partidos situados em países com desenvolvimento econômico ostentam maiores níveis de coerência.

Embora os indicadores das dimensões e subdimensões estabelecidas apareçam explicados tanto por variáveis exógenas como endógenas, ao contrario de nossa intuição ao propor o modelo teórico deste trabalho, as variáveis que aparecem como mais relevantes na análise de regressão não são as referidas à trajetória dos partidos políticos e de seus membros, mas as variáveis de caráter exógeno. Esse resultado faz com que fique pendente a pergunta de por que partidos de um mesmo sistema partidário têm níveis diferentes de coerência partidária.

O esquema geral das relações encontradas pode ser visto na Quadro 2, onde se observa graficamente que a dimensão programática da coerência partidária e a coerência total são influenciadas somente pelo desenvolvimento econômico do país em que se situam os partidos e que a dimensão ideológica, além de ser influenciada pelo grau de desenvolvimento socioeconômico, o é também pela variável endógena ideologia do partido. Embora seja perfeitamente compreensível que nos países com mais desenvolvimento econômico os partidos mostrem mais coerência, cremos que devemos fugir da tendência que atribui generalizações às variáveis econômicas. É preciso continuar na busca de novas variáveis explicativas da coerência partidária. Nesse sentido, seria conveniente explorar modos de operacionalizar acertadamente variáveis como o tamanho do partido, o contexto em que nasce, os tipos de eleições internas que existem e o tipo de liderança, e investigar sua incidência sobre a coerência partidária. 


\section{QUADRO 2}

Esquema geral das relações encontradas no modelo

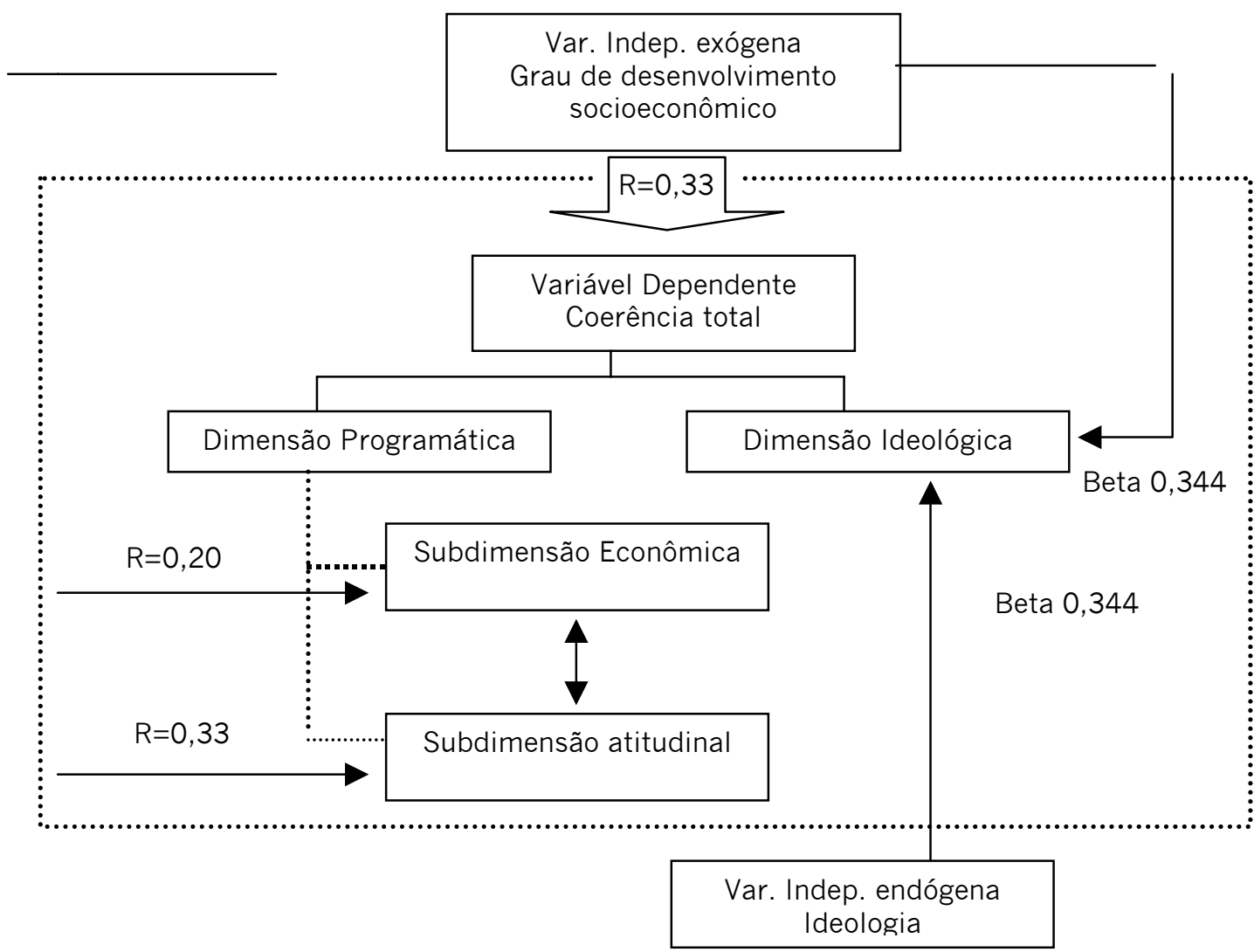




\section{TABELA 11}

\section{Resumo dos resultados}

Coerência ideológica

Variáveis que aparecem com influência estatística

- Desenvolvimento econômico do país

- Ideologia do partido

$R^{2}=0,483 \quad R^{2}$ corrigido $=0,436$ Durbin e Watson=2,233

\begin{tabular}{l|l|l} 
Beta estandardizado & $t$ & Sig \\
$-0,562$ & $-3,633$ & 0,001 \\
0,344 & 2,223 & 0,037
\end{tabular}

Papel das Forças Armadas

Variáveis que aparecem com influência estatística

-Número efetivo de partidos nas últimas eleições legislativas

$\mathrm{R}^{2}=0,365 \quad \mathrm{R}^{2}$ corrigido $=0,337$ Durbin e Watson=2,060

ANOVA $\quad F=10,288 \quad$ Sig $=0,001$

Valores cristãos ou seculares em política

Variáveis que aparecem com influência estatística

-Idade do partido

- Número efetivo de partidos nas últimas eleições legislativas

$R^{2}=0,452 \quad R^{2}$ corrigido $=0,402$ Durbin e Watson=2,077

\begin{tabular}{|l|l|l}
\hline Beta estandardizado & $t$ & Sig \\
\hline$-0,604$ & $-3,633$ & 0,001 \\
\hline ANOWA & F
\end{tabular}

ANOVA $\quad F=13,200 \quad$ Sig $=0,001$

Divórcio

Variáveis que aparecem com influência estatística

- Ideologia do partido

- Freqüência con que se falava de política

$\mathrm{R}^{2}=0,355 \quad \mathrm{R}^{2}$ corrigido $=0,296$ Durbin e Watson=2,293

\begin{tabular}{|c|c|c|}
\hline Beta estandardizado & $\mathrm{t}$ & Sig \\
\hline$-0,771$ & $-4,177$ & 0,000 \\
\hline$-0,532$ & $-2,884$ & 0,009 \\
\hline
\end{tabular}

Aborto

Variáveis que aparecem com influência estatística

- Média de anos de militância partidária dos legisladores

- Desenvolvimento econômico do país

- Nivel de Estudos

$R^{2}=0,492 \quad R^{2}$ corrigido $=0,42$ Durbin e Watson=1,561

Coerência programática-atitudinal

Variáveis que aparecem com influência estatística

- Desenvolvimento econômico do país

$\mathrm{R}^{2}=0,190 \quad \mathrm{R}^{2}$ corrigido $=0,155$ Durbin e Watson=1,735

\begin{tabular}{|l|l|l|l}
\hline Beta estandardizado & $t$ & Sig \\
\hline 0,455 & 2,632 & 0,015 \\
\hdashline$-0,361$ & $-2,104$ & 0,047 \\
\hline ANOVA & $F=6,042$ & Sig= 0,008 \\
\hline
\end{tabular}

Estatismo-mercado

Variáveis que aparecem com influência estatística

- Desenvolvimento econômico do país

$\mathrm{R}^{2}=0,27 \quad \mathrm{R}^{2}$ corrigido $=0,24$ Durbin e Watson=2,175

Intervenção do Estado como via para reduzir as desigualdades

Variáveis que aparecem com influência estatística

- Desenvolvimento econômico do país

- Nivel de Estudos

$R^{2}=0,389 \quad R^{2}$ corrigido $=0,333$ Durbin e Watson=2,064

\begin{tabular}{|l|l|l}
\hline Beta estandardizado & $t$ & Sig \\
\hdashline 0,712 & 3,985 & 0,001 \\
\hdashline$-0,631$ & $-3,485$ & 0,002 \\
\hline 0,414 & 2,219 & 0,038 \\
\hline ANOVA & $F=5,401$ & Sig=0 \\
\hline
\end{tabular}

Coerência programática-econômica

Variáveis que aparecem com influência estatística

Desenvolvimento econômico do país

$R^{2}=0,234 \quad R^{2}$ corrigido $=0,201$ Durbin e Watson=2,049

Coerência total

Variáveis que aparecem com influência estatística

- Desenvolvimento econômico do país

$R^{2}=0,363 \quad R^{2}$ corrigido $=0,335$

\begin{tabular}{|l|l|l|}
\hline Beta estandardizado & $t$ & Sig \\
\hline$-0,436$ & $-2,324$ & 0,029 \\
\hline ANOVA $F=6,794$ & Sig= 0,029
\end{tabular}

Sig= 0,029

\begin{tabular}{|c|c|c|}
\hline Beta estandardizado & $t$ & Sig \\
\hline$-0,524$ & $-2,950$ & 0,007 \\
\hline
\end{tabular}

\section{Fonte: Elaboração própria}




\section{Conclusões}

Em termos teóricos, a análise realizada oferece três contribuições. Por um lado, contribui para esclarecer o panorama de confusão conceitual em torno do conceito de coerência que, neste trabalho, fica restrito ao âmbito das posiçõesatitudes-opiniões dos membros de um partido, deixando de lado a dimensão do comportamento deles. Por outro lado, faz-se uma distinção da coerência partidária em duas dimensões: ideologia e programa. Considerou-se que dimensão programática é formada por duas subdimensões: a referida a termos valorativos e a referida a aspectos econômicos. Junto a essas duas questões teóricas, defende-se a idoneidade do partido político como unidade de análise no momento de estudar a coerência partidária.

Em termos substantivos são duas as principais conclusões deste trabalho. Em primeiro lugar, com relação à descrição da coerência, existem graus variáveis de coerência nos partidos políticos latino-americanos que permitem classificá-los a em função do grau de congruência ideológica e programática. Além disso, o estudo da coerência aponta que ideologia e programa são dimensões que devem ser lavadas em conta para compreender a estruturação do jogo partidário na região latino-americana. Mas uma vez que se comprovou que as subdimensões programáticas guardam pouca relação entre si, a análise melhoraria com a inclusão de novos indicadores na operacionalização do conceito de coerência.

Nesse sentido, realizou-se a classificação dos partidos de acordo com o grau de coerência que manifestaram nas dimensões e subdimensões estabelecidas. Para tanto, criaram-se distintos indicadores que serviram como captura quantitativa dos elementos identificadores da coerência programática. Descobrimos principalmente que existem dois países, ambos do Cone Sul, que se caracterizam por ter um sistema partidário coerente: Chile e Argentina, embora os níveis altos de coerência estejam ocupados por partidos políticos pertencentes a dois sistemas. No lado da incoerência, a encontramos principalmente nos partidos centro-americanos e em dois partidos andinos: o PRE do Equador e o MVR da Venezuela.

Como segunda conclusão substantiva no que tange à explicação da coerência partidária, embora obscurecida pela combinação de uma grande quantidade de variáveis independentes e de um baixo número de casos, os fatores endógenos parecem ter muito menor força na análise do que os exógenos. Assim, o grau de desenvolvimento econômico aparece como o único elemento determinante do grau de coerência total de um partido político latino-americano. Contudo, parece difícil formular um argumento teórico nesse sentido. Por isso, é pertinente investigar em análises futuras os mecanismos causais que mediam a relação entre essas duas variáveis, ao mesmo tempo em que se deve seguir trabalhando na 
operacionalização de outros fatores explicativos, como pode ser o tipo de liderança dos partidos políticos.

Para finalizar, queremos ressaltar que este trabalho tratou da coerência como variável dependente, deixando de lado uma reflexão pendente, por sua indiscutível relevância, sobre o impacto da coerência sobre as diferentes dimensões do sistema político.

\section{BIBLIOGRAFIA}

ALCÁNTARA, Manuel. (1995) La élite parlamentaria latinoamericana y el continuo izquierdaderecha. In: HOFMEISTER, W. \& THESING, J. (eds.) Transformación de los sistemas políticos en América Latina. Buenos Aires, Konrad Adenauer Stiftung-CIEDLA. p.385-410

. (1999) La relación izquierda-derecha en los sistemas de partidos de Chile y México. Trabalho apresentado no IV Congresso da Asociación Española de Ciencia Política y de la Administración. Granada, 30 de setembro a 2 de outubro.

ALCÁNTARA, Manuel \& LLAMAZARES, Iván. (1997) El análisis de los diputados latinoamericanos en el contexto de los estudios sobre la clase política. Características, objetivos y estrategias de investigación. América Latina Hoy, 16: 15-28.

ALEXANDER, Robert J. (1972) Latin American political parties. Nova York, Praeger.

BOWLER, Shaun; FARRELL, David M. \& KATZ, Richard S. (eds.). (1999) Party discipline and parliamentary government. Ohio State University.

CAVAROZZI, Marcelo. (1995) Los partidos políticos latinoamericanos: sus configuraciones históricas y su papel en las transiciones recientes. In: ALCÁNTARA M. \& CRESPO, I. (orgs.) Los límites de la consolidación democrática en América Latina. Salamanca, Ediciones de la Universidad de Salamanca, p.145-157.

COPPEDGE, Michael. (1997) The dynamic diversity of Latin American party systems. In: http://www.nd.edu:80/ mcoppedg/crd/ddlaps.htm.

CRESPO, Ismael \& MIERES, Pablo. (1997) La clase parlamentaria uruguaya. Cultura política y diseños institucionales. Perfiles Latinoamericanos, 11:9-42.

DIAMOND, Larry; HARTLYN, Jonathan, LINZ, Juan J. \& LIPSET, Seymour Martin (eds.). (1999) Democracy in developing countries. Latin America. Boulder, Colorado, Lynne Rienner Publishers.

DIX, Robert H. (1989) Cleavage structures and party systems in Latin America. Comparative Politics, 22(1):23-37.

DOWNS, Anthony. (1957) An economic theory of democracy. Nova York: Harper and Row.

GARCÍA DÍEZ, Fátima. (2001) Guatemala: Frente Republicano guatemalteco. In: ALCÁNTARA SÁEZ, Manuel \& FREIDENBERG, Flavia. (2001) Partidos políticos de América Latina. Salamanca, Ediciones de la Universidad de Salamanca.

GUNTHER, Richard, ed. (1992) Elites and democratic consolidation in Lain America and Southern Europe. Cambridge, Cambridge University Press.

HARTLYN, Jonathan \& VALENZUELA, Arturo. (1998) Democracy in Latin America since 1930. In: BETHELL, Leslie (ed.). Latin America. Politics and society since 1930. Londres, Cambridge University Press, p.3-66. 
HAWKINS, Kirk \& MORGENSTERN, Scott. (2000) Cohesion of legislators in Latin America: patterns and explanations. Trabalho preparado para apresentar na reunião anual da American Political Science Association, Washington.

HINE, David. (1982) Factionalism in Western European parties. A framework for analysis". Western European Politics, (5)1.

JANDA, Kenneth. (1993) Comparative political parties: research and theory. In: FINIFTER, A. W. Political Science: the state of the Discipline II. Washington, D.C.: American Political Science Association, p.163-191.

KITSCHELT, Herbert. (2000) Party cohesion, accountability, and responsiveness. Democratic institutions and political-economic change. Trabalho preparado para apresentar na reunião anual da American Political Science Association, Washington.

(2001) Party and party system dynamics in Latin America. An inductive comparative exploration prompted by the Salamanca 1997-98 politician's survey.

KITSCHELT, Hertbert et al. (1999) Post-Communist party systems. Competition, representation and inter-party cooperation. Cambridge, Cambridge University Press.

LEVITSKY, Steven. (1998) Institutionalization and Peronism. The concept, the case and the case for unpacking the concept. Party Politics, 4(1):77-92.

LINZ, Juan J. \& VALENZUELA, Arturo (orgs.). (1994) The failure of presidential democracies. Boulder, Colorado, Westview Press.

LIPSET, Seymour M. \& SOLARI, Aldo (ed.) (1987) Elites in Latin America. Nova York, Oxford University Press.

LLAMAZARES, Iván \& SANDELL, Rick. (2000) Partidos Políticos y dimensiones ideológicas en Argentina, Chile, México, Uruguay. Esbozo de un análisis espacial. Trabalho apresentado no Institute of Latin American Studies, University of London, fevereiro.

LONDREGAN, John. (1999) Ideology and legislative institutions in Chile's transition towards Democracy. (s/i)

MAINWARING, Scott. (1998) Rethinking party systems theory in the third wave of democratization. The importance of party system institutionalization. Working Paper, 260, Indiana, Kellog Institute for International Studies-University of Notre Dame.

MAINWARING, Scott \& SCULLY, Timothy. (eds.) (1995) Party systems in Latin America. Stanford, Stanford University Press.

MAINWARING, Scott \& SHUGART, Mathew S. (orgs.). (1997) Presidentialism and democracy in Latin America. Cambridge, Cambridge University Press.

MAINWARING, Scott \& TORCAL, Mariano. (2000) The political recrafting of social bases of party competition: Chile in the 1990s. Working Paper, 278, Indiana, Kellog Institute for International Studies-University of Notre Dame..

MAOR, Moshe. (1997) Cohesion and Dissent. In: MAOR, M. Political parties and party systems. Comparative approaches and the British experience. Londres, Routledge, p.135-165.

MARTÍNEZ RODRÍGUEZ, Antonia. (1997a) Cultura política, gobernabilidad y élites parlamentarias en América Latina. Revista Mexicana de Sociología, 59(1):89-114.

Latinoamericanos, 11: 43-70.

(1997b) Diputados, clivajes y polarización en México. Perfiles

MIDDLEBROOK, Kevin J. (ed.). (2000) Conservative Parties, the right, and democracy in Latin America. Baltimore, Johns Hopkins University Press. 
MORENO, Alejandro. (1999) Political cleavages. Issues, parties and the consolidation of democracy. Boulder, Colorado, Westview Press.

NORRIS, Pippa. (1997) Passages to power. Legislative recruitment in advanced democracies. Cambridge, Cambridge University Press.

PEREIRA ALMAO, Valia. (2001) Venezuela: Movimiento V República. In: ALCÁNTARA SÁEZ, Manuel \& FREIDENBERG, Flavia. (2001) Partidos políticos de América Latina. Salamanca, Ediciones de la Universidad de Salamanca.

PIERRE, Joh. (1986) Attitudes and behaviour of party activists. A critical examination of recent research on party activists and 'Middle-Level Elites'. European Journal of Political Research, 14: 465-479.

RAMOS JIMÉNEZ, Alfredo. (1995) Los partidos políticos en las democracias latinoamericanas. México, FCE.

RAMOS ROLLÓN, Marisa. (1997) Variables determinantes de las creencias y los valores de la élite parlamentaria en Venezuela. Revista Mexicana de Sociología, 59(1):69-88.

ROSAS, Guillermo. (2000) Policy preferences, political competition, and ideology in Latin American legislatures. Trabalho apresentado na reunião da American Political Science Association, Washington.

ROSAS, Guillermo e Elizabeth Zeichemester. (2000)

http://136.142.158.105/2000PDFF/Rosa\&Zechmeister.PDF

SANI, Giacomo \& SARTORI, Giovanni. (1983) Polarization, fragmentation and competition in Western democracies. In: DAALDER P. \& MAIR, P. (eds.). Western European Party Systems. Beverly Hills, Sage, p.307-340.

SARTORI, Giovanni. (1991) Partidos y sistemas de partidos. Madri, Alianza.

SANTIUSTE CUÉ, Salvador. (2001) Nicaragua. In: ALCÁNTARA SÁEZ, Manuel \& FREIDENBERG, Flavia. (2001) Partidos políticos de América Latina. Salamanca, Ediciones de la Universidad de Salamanca.

SCHEDLER, Andreas. (1995) Under and overinstitutionalization: some ideal typical propositions concerning new and old party systems. Working Paper, 213, Indiana, Kellogg Institute for International Studies-University of Notre Dame.

VAIVADS, Henry. (2001) Venezuela: Acción Democrática. In: ALCÁNTARA SÁEZ, Manuel \& FREIDENBERG, Flavia. (2001) Partidos políticos de América Latina. Salamanca, Ediciones de la Universidad de Salamanca.

YOCELEVZKY, R. (1997) Democratización y recomposición del sistema político en Chile. In: YOCELEVZKY, R. (coord.) Experimentos con la democracia en América Latina. México, Universidad Autónoma Metropolitana, p.125-146.

ZECHMEISTER, Elizabeth J. (2000) Left and Right in Latin America. Trabalho preparado para apresentar na reunião anual da American Political Science Association, Washington. 
OPINIÃO PÚBLICA,Campinas, Vol.VIII, n², pp.189-229

ANEXO I

Ficha Técnica Pesquisa de Elites Parlamentares na América Latina

\begin{tabular}{lcccc}
\hline $\begin{array}{c}\text { Grupo } \\
\text { Parlamentar }\end{array}$ & $\begin{array}{c}\text { Distribuição de } \\
\text { assentos por partido }\end{array}$ & $\%$ & $\begin{array}{c}\text { Número de legisladores } \\
\text { entrevistados }\end{array}$ & $\%$ \\
\hline Chile 98 & & & & \\
PDC & 39 & 32,50 & 29 & 32,58 \\
UDI & 23 & 19,17 & 17 & 19,10 \\
RN & 23 & 19,17 & 17 & 19,10 \\
PPD & 16 & 13,33 & 12 & 13,48 \\
PS & 11 & 9,17 & 8 & 8,99 \\
Outros partidos & 8 & 6,67 & 6 & 6,74 \\
Total & 120 & 100,00 & 81 & 100,00 \\
\hline
\end{tabular}

Erro de amostra: Para um nível de confiança de 95,5\% (dois sigmas), e $P=Q$, o erro teórico é de $\pm 5,5$

El Salvador 2000

\begin{tabular}{lrrrr} 
ARENA & 31 & 36,9 & 20 & 31,3 \\
FMLN & 29 & 34,5 & 25 & 39,1 \\
PCN & 14 & 16,7 & 11 & 17,2 \\
Outros & 10 & 11,9 & 8 & 12,5 \\
\hline Total & 84 & $100,0($ & 64 & 100,00 \\
\hline
\end{tabular}

Erro de amostra: Para um nível de confiança de 95,5\% (dois sigmas), e $P=Q$, o erro teórico é de $\pm 6,75$

Guatemala 98

\begin{tabular}{lrrrr} 
PAN & 44 & 55,00 & 35 & 55,56 \\
FRG & 18 & 22,50 & 14 & 22,22 \\
Outros partidos & 18 & 22,50 & 14 & 22,22 \\
\hline Total & 80 & 100,00 & 63 & 100,00 \\
\hline Honduras 98 & & & & \\
PL & 67 & 52,34 & 37 & 52,11 \\
PN & 55 & 42,97 & 30 & 42,25 \\
Outros partidos & 6 & 4,69 & 4 & 5,63 \\
\hline Total & 128 & 100,00 & 71 & 100,00 \\
\hline Nicarágua 98 & & & & \\
PLC & 42 & 45,16 & 32 & 45,71 \\
FSLN & 36 & 38,71 & 27 & 38,57 \\
Outros partidos & 15 & 16,13 & 11 & 15,72 \\
Total & 93 & 100,00 & 70 & 100,00 \\
\hline
\end{tabular}

(continua) 
(continuação do ANEXO I)

\begin{tabular}{|c|c|c|c|c|c|}
\hline $\begin{array}{c}\text { Grupo } \\
\text { Parlamentar }\end{array}$ & \multicolumn{2}{|c|}{$\begin{array}{c}\text { Distribuição de } \\
\text { assentos por partido }\end{array}$} & $\%$ & $\begin{array}{c}\text { Número de legisladores } \\
\text { entrevistados }\end{array}$ & $\%$ \\
\hline \multicolumn{6}{|l|}{ Argentina 98} \\
\hline PJ & \multicolumn{2}{|c|}{119} & 46,3 & 59 & 46,1 \\
\hline UCR & \multicolumn{2}{|c|}{68} & 26,5 & 34 & 26,5 \\
\hline FREPASO & \multicolumn{2}{|c|}{38} & 14,8 & 19 & 14,8 \\
\hline Outros partidos & \multicolumn{2}{|c|}{32} & 12,4 & 16 & 12,5 \\
\hline Total & \multicolumn{2}{|c|}{257} & 100,0 & 128 & 100,0 \\
\hline \multicolumn{6}{|c|}{ Erro de amostra: Para um nível de confiança de $95,5 \%$ (dois sigmas), e $P=Q$, o erro teórico é de $\pm 6,39$} \\
\hline \multicolumn{6}{|l|}{ Colômbia 98} \\
\hline PL & 83 & 51,55 & 48 & \multicolumn{2}{|l|}{54,55} \\
\hline PC & 43 & 26,71 & 29 & \multicolumn{2}{|l|}{32,95} \\
\hline Outros partidos & 35 & 21,74 & 11 & \multicolumn{2}{|l|}{12,50} \\
\hline Total & 161 & 100,00 & 88 & \multicolumn{2}{|l|}{100,00} \\
\hline \multicolumn{6}{|c|}{ Erro de amostra: Para um nivel de confiança de $95,5 \%$ (dois sigmas), e $P=Q$, o erro teórico é de $\pm 5,98$} \\
\hline \multicolumn{6}{|c|}{ República Dominicana 2000} \\
\hline PRD & 68 & 45,3 & 47 & \multicolumn{2}{|l|}{45,6} \\
\hline PLD & 49 & 32,7 & 34 & \multicolumn{2}{|l|}{33,0} \\
\hline PRSC & 17 & 11,3 & 11 & \multicolumn{2}{|l|}{10,7} \\
\hline Outros partidos & 16 & 10,7 & 11 & \multicolumn{2}{|l|}{10,7} \\
\hline Total & 150 & 100,00 & 103 & \multicolumn{2}{|l|}{100,00} \\
\hline \multicolumn{6}{|c|}{ Erro de amostra: Para um nível de confiança de $95,5 \%$ (dois sigmas), e $P=Q$, o erro teórico é de $\pm 4,61$} \\
\hline \multicolumn{6}{|l|}{ Venezuela 2000} \\
\hline MVR & 77 & 46,7 & 47 & \multicolumn{2}{|l|}{47,0} \\
\hline$A D$ & 31 & 18,8 & 16 & \multicolumn{2}{|l|}{16,0} \\
\hline MAS & 21 & 12,7 & 12 & \multicolumn{2}{|l|}{12,0} \\
\hline COPEI & 7 & 4,2 & 6 & \multicolumn{2}{|l|}{6,0} \\
\hline PRVZL & 7 & 4,2 & 4 & \multicolumn{2}{|l|}{4,0} \\
\hline Outros & 22 & 13,3 & 15 & 15,0 & \\
\hline Total & 165 & 100,00 & 100 & 100,00 & \\
\hline
\end{tabular}




\section{ANEXO //}

\section{Indicadores da Dimensão ideológica}

\section{- Autolocalização ideológica}

Pergunta feita (p. 67) Como deve lembrar,quando se fala de política normalmente se utilizam as expressões esquerda e direita. Neste cartão há uma série de casas que vão de esquerda à direita. Em que casa você se colocaria, levando em conta suas idéias políticas? A variável é medida em escala de 1 a 10. Eliminaram-se os NS/NR

\section{Indicadores da Subdimensão programática-atitudinal}

\section{-Papel das Forças Armadas}

Pergunta feita (p.31): Em uma escala de 1 al 10, onde 1 é muito negativo e 10 muito positivo, como você avalia o papel das Forças Armadas em seu país na atualidade?

A variável é medida em escala de 1 a 10. Eliminaram-se os NS/NR

\section{- Grau de religiosidade}

Pergunta feita (p.70.a): De acordo com seus sentimentos e crenças religiosas, em que posição da seguinte escala você se colocaria, sabendo que "1" significa um mínimo de religiosidade e prática religiosa e "10" um máximo de religiosidade e prática religiosa?

A variável é medida em escala de 1 a 10. Eliminaram-se os NS/NR.

\section{- Valores cristãos ou seculares em política}

Pergunta feita (p.70.b): Para terminar com este tema, poderia dizer-se me você é a favor da presença dos valores cristãos na política ou dos princípios seculares? Utilize para isso a seguinte escala de 1 a 5, onde "1" significa a máxima inclinação pela presença dos valores cristãos na política e "5" a máxima inclinação pela presença dos princípios seculares na política.

A variável é medida em escala de 1 a 5. Eliminaram-se os NS/NR.

\section{- Divórcio}

Pergunta feita (p. 73): Qual é sua opinião pessoal sobre o divórcio?

(1) Totalmente a favor, (2) Deveriam ampliar os casos regulados pela legislação vigente, (3) Somente se deveria admitir nos casos regulados pela legislação vigente, (4) Se deveria limitar os casos regulados pela legislação vigente, (5) Totalmente contra.

Utiliza-se uma escala em que 1 é totalmente a favor, 5 totalmente contra. Eliminaram-se os NS/NR. 


\section{- Aborto}

Pergunta feita (p. 74): E sua opinião geral sobre o aborto?

(1) Totalmente a favor, (2) Deveriam ampliar os casos regulados pela legislação vigente, (3) Somente se deveria admitir nos casos regulados pela legislação vigente, (4) Se deveria limitar os casos regulados pela legislação vigente, (5) Totalmente contra.

Utiliza-se uma escala em que 1 é totalmente a favor, 5 totalmente contra. Eliminaram-se os NS/NR.

-Importância concedida aos direitos humanos ou das minorias étnicas ou culturais.

Pergunta feita (p37. 11): Em seguida, vou enumerar uma série de problemas comuns a muitos países. Poderia indicar-me, para cada um deles, que grau de importância: muita, bastante, pouca ou nenhuma têm hoje em seu país?

Recodificou-se como dicotômica, onde 1 é muita e bastante importância e 0 é pouca ou nenhuma importância. Eliminam-se os NS/NR.

\section{Indicadores da Subdimensão programática-econômica}

\section{- Estatismo-mercado}

Pergunta feita (p.34.a ) Como você sabe, existe atualmente um profundo debate entre as posições estatizantes e neoliberais em diversos países do continente. A respeito disso, você poderia me dizer sei está mais a favor de uma economia regulada pelo Estado ou pelo mercado? Utilize para isso a seguinte escala de 1 a 5, onde " 1 " significa uma máxima presença estatal na economia e "5" uma máxima regulação através do mercado.

Utiliza-se como escala 1 totalmente a favor, 5 totalmente contra. Eliminaram-se os NS/NR.

\section{- Impostos diretos ou indiretos}

Pergunta feita (p.40): E levando em conta que para gastar mais poderia ser necessário aumentar os impostos, como você acha que se deveria financiar este aumento, através de impostos diretos ou indiretos?

Recodificou-se como dicotômica, onde 1 é através de impostos diretos e 0 é através de impostos indiretos. Eliminaram-se os NS/NR.

\section{- A intervenção do Estado na vida socioeconômica é a única maneira possível de reduzir as desigualdades}

Pergunta feita (p34.2): Na atualidade, se discute bastante sobre o papel do Estado. Neste sentido, você poderia me dizer se está mais de acordo ou mais em desacordo com cada uma das seguintes afirmações?

Recodificou-se como dicotômica, onde 1 é de acordo e 0 é em desacordo. Eliminaram-se os NS/NR. 


\section{Variáveis independentes}

\section{Endógenas:}

-Idade do partido

Medida em anos, desde a data da fundação do partido, até o ano em que se fez a entrevista de Elites Parlamentares Latino-americanas.

\section{-Ideologia do partido}

Pergunta feita (p.17) Quando se fala de política, se utilizam normalmente as expressões esquerda e direita. Em uma escala em que 1 é a esquerda e 10 a direita, em que casa você colocaria os seguintes partidos ou coalizões?

Para o cálculo da ideologia do partido realizou-se uma média a partir das pontuações dadas na escala de 1.10 por parte dos legisladores pertencentes ao resto dos partidos.

\section{-Média de anos de militância em organizações partidárias}

Pergunta feita (p.52) Em que ano você começou a militar em um partido político pela primeira vez?

Calculou-se a média de anos de militância dos legisladores entrevistados para cada partido.

\section{-Nível de estudos}

Pergunta feita (76) Quais são os estudos de mais alto nível que você fez?

Calcula-se a média do nível de estudos dos legisladores entrevistados de cada partido, de acordo com a escala em que 1 é nenhum estudo e 6 estudos de pós-graduação.

-Idade média dos legisladores do partido

Pergunta feita (p.72) Quantos anos você fez em seu último aniversário?

Calculou-se a idade média dos legisladores entrevistados para cada partido político.

-Freqüência com que se falava de política durante sua infância e juventude

Pergunta feita (p.62) Com que freqüência: muita, bastante, pouca ou nenhuma, se falava de política em sua casa durante sua infância e juventude?

Recodificou-se como dicotômica, onde 1 é com muita e bastante freqüência e 0 é com pouca ou nenhuma freqüência. Eliminaram-se os NS/NR e calcula-se a média das pontuações oferecidas pos legisladores entrevistados para cada partido político.

\section{-Se é a primeira legislatura em que é deputado}

Pergunta feita (p.54) É esta a primeira legislatura em que você foi eleito deputado?

Recodificou-se como dicotômica, onde 1 significa que é a primeira legislatura em que foi deputado e 0 significa que não é a primeira vez que é deputado. Eliminaram-se os NS/NR e calcula-se a média das pontuações oferecidas pelos legisladores entrevistados para cada partido político. 


\section{Exógenas:}

-Número efetivo de partidos nas últimas eleições legislativas

Calculou-se para cada país o número efetivo de partidos nas eleições legislativas das quais saiu a composição da Legislatura cujos deputados são entrevistados.

\section{-Desenvolvimento econômico do país}

Esta variável foi medida através do PIB por habitante. Base de Dados do DEM-IECI em Claves de la Economía Mundial (2000). Madri: ICEX. 